NBSIR 80-2072

\title{
X-Cal - A Calibration System for Electrical Measurement Devices Used With Diagnostic X-Ray Units
}

Ronald H. McKnight and Robert E. Hebner, Jr.

Electrosystems Division

Center for Electronics and Electrical Engineering National Bureau of Standards

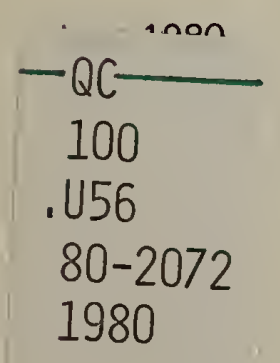

Prepared tor:

Calibration Coordination Group

Department of Defense

DoD/CCG Project 78-130 

Ronald H. McKnight and Robert E. Hebner, Jr.

Electrosystems Division

Center for Electronics and Electrical Engineering National Bureau of Standards

June 1980

Prepared for:

Calibration Coordination Group

Department of Defense

DoD/CCG Project 78-130

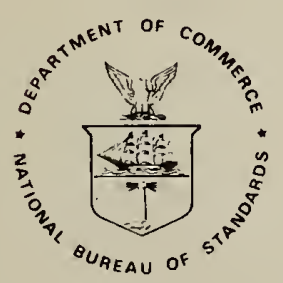

U.S. DEPARTMENT OF COMMERCE, Philip M. Klutznick, Secretary

Luther H. Hodges, Jr., Deputy Secretary

Jordan J. Baruch, Assistant Secretary for Productivity, Technology, and Innovation NATIONAL BUREAU OF STANDARDS, Ernest Ambler, Director 

Table of Contents

Abstract ............................. i

Introduction .................... . . 1

Specifications ................... 2

Theory ....................... . . 5

System Description ................ . . 21

Installation ...................... 27

Operating Instructions . . . . . . . . . . . 31

Calibration Information . . . . . . . . . . 46

Maintenance and Calibration ............. 50

Parts List . . . . . . . . . . . . . . . . 51

Circuit Diagrams ..................... 53

References ................. . . 70

Acknowledgments ....................... 71 

Abstract

A high-voltage-divider calibration system (designated as X-CAL System) was designed to calibrate the direct and alternating voltage measurement capabilities of commercial high voltage dividers used to characterize diagnostic $x$-ray units. The system includes capability for determining the frequency response of these dividers and for the calibration of the filament current and anode current measurement features of specific commercially-available devices. The calibration system combines in a single unit a range of capabilities which allows calibration of a device under test to be accomplished with a minimum of set up time. This report describes the rationale for measuring certain parameters of the high voltage dividers. It provides the design details of the X-CAL system and certain sections of this report serve as the operating manual for the system. The report lists the specified accuracies and the ranges of applicable parameters of the various subsystems, describes the five different calibrations which can be performed using the X-CAL system, discusses techniques used in the original calibration of the X-CAL system itself, and contains the basic circuit diagrams for the system. 



\section{Introduction}

The X-CAL high voltage divider calibration system was designed to calibrate the direct and alternating voltage measurement capabilities of commercial high voltage dividers used to electrically characterize diagnostic $x$-ray units. In addition there is capability for determining the frequency response of these dividers. This set of measurements as applied to dividers used to characterize diagnostic $x$-ray units was developed at NBS and is a part of the calibration services of NBS. The X-CAL system was developed for and with the support of the Calibration Coordination Group (CCG) of the Department of Defense. It will be used to routinely calibrate divider units used in military hospitals as part of a service-wide effort to control radiation exposure. Because of CCG requirements, two test functions have been included in X-CAL for the calibration of special measurement features of one particular device, the Machlett Dynalyzer. ${ }^{1}$ These are filament current and anode current measurements. With minor X-CAL system modification, these test functions can be used to calibrate any measurement system offering these capabilities. The calibration system combines in a single unit a range of capabilities which allows calibration of a device under test (DUT) to be accomplished with a minimum of set up time.

This report is intended to give a user, or potential user, a description of the motivation for, the operation of and the design details of the $\mathrm{X}$-CAL system. It is also intended and is written appropriately to serve as an operating manual for the system. Section 2 lists the specified accuracies and the ranges of applicable parameters of the various subsystems. The motivation for the various electrical measurements is described in Section 3. Section 4 describes the five different calibrations which can be performed 
using the X-CAL system. System installation is described in Section 5 . Detailed operating instructions are given in Section 6 . Section 7 discusses techniques used in the original calibration of the X-CAL system itself. Section 8 describes maintenance and recalibration procedures for the $\mathrm{X}$-CAL system. A suggested list of replacement parts is given in Section 9. Section 10 contains the basic circuit diagrams for the system and Section 11 is a list of references.

\section{Specifications}

The X-CAL calibration system allows five specific calibrations to be performed. These are listed below with statements of accuracies and ranges of applicable parameters.

2.1 Direct Voltage Divider Ratio Measurement

Voltage Range - 0 to $\pm 75 \mathrm{kV}$.

Accuracy of measurement - $\pm 7 \%$.

2.2 Alternating Voltage Divider Ratio Measurement

Voltage Range - determined by power supply provided by user.

Accuracy of measurement - $\pm 1 \%$ using calibrated standard high-voltage gas-filled capacitor.

2.3 Frequency Response of Divider Ratio

Frequency Range - fixed frequency oscillator (50, $100,500,1000,5000,10000 \mathrm{~Hz}$ ) or variable frequency function generator.

Accuracy of measurement - $\pm 1 \%$ for ratios normalized to de ratio values.

\subsection{Filament Current}

Current Range - continuously variable from 0 to 20 amps for a 1 ohm load. 
Accuracy of measurement $- \pm 7 \%$.

2.5 Anode Current

Current Range - selectable from 0.05 amp to $2 \mathrm{amp}$ $(0.05,0.1,0.5,1,2)$ into a 200 ohm load.

Current Pulse Width - selectable from $0.01 \mathrm{~s}$ to $1 \mathrm{~s}$

$(0.01,0.05,0.1,0.5,1)$ with current pulse controller

limiting average power to 10 watts.

Accuracy of measurement - $\pm 1 \%$. This accuracy statement

is for the current pulses driving the $200 \mathrm{ohm}$ load of a

Machlett Dynalyzer ${ }^{7}$ when the peak current value is converted

into the corresponding average current value. The table

of conversion factors is in Section 6 .

The measurements described in 2.5 and 2.6 are designed specifically for a Machlett Dynalyzer ${ }^{1}$ system and the specifications apply only to measurements on this system. The adaptation of the X-CAL system for calibration of other units is detailed in Section 6.8.

2.6 Description of System Modules and Specific Control Functions The following sections describe the system components which were specially developed for the X-CAL system. Commercially available items have been used when possible and the instruction manuals for these items should be referred to for details of their operation.

2.7 System Control Module Switches

Power - Turns on control module and activates control circuitry. Other calibration system modules have independent power switches.

Test Function - Enables appropriate test circuitry and routes test signals. Five separate test modes may be selected: DCHV, ACHV, FREQ Res, ANODE I, and FIL I. 
A/C - Selects for processing either the anode or cathode output signal from the DUT.

Active/Passive - Differentiates between signals generated by devices under test which contain active signal processing components and passive devices. In the ACTIVE position, the signal is routed to the appropriate signal processing circuits. When the passive mode is selected, the input signal is amplified by an amplifier, the gain of which can be selected (by resistor replacement and trim pot adjustment) to provide direct readout from the DUT.

Signal - INT/EXT - Determines the source of the low level signal used in the frequency response measurements. In the INT position, switch selectable discrete frequencies are available. For more extensive measurements, the EXT position allows use of a separate function generator.

Ratio Trans - HI/LO - Selects either the high frequency or low frequency sections of the ratio transformer for use in frequency response measurements.

Frequency - Sets the frequency of the internal oscillator to one of six values.

Reset - Resets the peak and hold detector used in the ACHV measurement circuit.

2.8 Filament Current-Viewing-Resistor Test Module Pwr - turns on ac supply but does not control the ac panel meter.

AC I - Current control

AC Panel Meter - Indicates current in external circuit directly. Unless the FIL I test mode is selected, the meter display is blanked. 
2.9 Anode-Current-Viewing-Resistor Test Unit

Pwr - Energizes main dc supply.

Peak Current - Selects nominal value of peak current produced in a $200 \mathrm{ohm}$ external load.

Pulse Duration - Selects pulse length. Peak current and pulse duration circuitry are configured to limit average power dissipation in a $200 \mathrm{ohm}$ load to $10 \mathrm{~W}$.

Peak Current Meter - Indicates peak current produced by unit.

\section{Theory}

It has been estimated that exposure to medical and dental $x$-rays is the source of 90 percent of the population dose from man-made sources. ${ }^{2}$ The $x$-ray dose produced by an $x$-ray unit depends on $x$-ray tube construction, the waveform of the potential difference across the tube, the current through the tube and the duration of the voltage pulse. In practice the operator has control of the last three parameters, and of these, the peak potential difference across the tube is most important. There are two different techniques used to determine the peak voltage level in diagnostic $x$-ray units. ${ }^{3-12}$ One is to infer the peak voltage from a measurement of appropriate parameters of the emitted beam of $x$-rays. The other is to perform an electrical measurement of the voltage using conventional high voltage measurement techniques. The relative advantages of various measurement methods have been discussed and the consistency of these measurements (under a limited range of voltage and time parameters of pulses), when used to measure the same voltage waveform, has been determined by other workers. 5,11 
Unnecessary radiation exposure can result when the operation of diagnostic $x$-ray equipment is not well characterized. Direct measurements of $x$-ray energy spectrum and dose during each exposure are presentiy impractical. However, one means of controlling radiation exposure is to insure the accuracy of the measurement of electrical quantities associated with diagnostic $x$-ray units.

The X-CAL unit provides electrical calibration of devices which perform electrical measurements on diagnostic $x$-ray units. Because high voltage measurements are made in a large number of applications outside the field of diagnostic radiology, the application of standard calibration techniques to $x$-ray unit high voltage dividers insures the consistency of the calibration of the measurement apparatus to within the specified uncertainty of the measurements among users of high voltage apparatus.

A basic theoretical model ${ }^{13}$, which has been used to describe pulse dividers, represents the divider as a matrix relating the input current and voltage to the output current and voltage:

$$
\left[\begin{array}{ll}
V_{\text {in }}(\omega) \\
I_{\text {in }}(\omega)
\end{array}\right]=\left[\begin{array}{llll}
A_{11} & (\omega) & A_{12}(\omega) \\
A_{21} & (\omega) & A_{22} & (\omega)
\end{array}\right] \cdot\left[\begin{array}{ll}
V_{0} & \left(\omega_{\prime}^{\prime}\right. \\
I_{0} & (\omega)
\end{array}\right]
$$

From Eq. 1, two parameters of the divider are defined. One is the voltage transfer function, $H(\omega)$, which is the ratio of the output voltage to the input voltage when the output current is zero, i.e.,

$$
H(\omega)=V_{0}(\omega) / V_{\text {in }}(\omega)_{I_{0}(\omega)=0}=1 / A_{11}(\omega) .
$$

The other is the divider ratio, $\mathrm{N}$, which is defined as 


$$
N=A_{11}(0)=\lim _{\omega \rightarrow 0} A_{11}(\omega)
$$

To apply these equations to the dividers under test, it is useful to consider the circuit in Fig. 3.1. The model is not adequate to predict the exact shape of the frequency response of al1 the dividers tested, but from this model, many of the significant properties of the device can be inferred. For example, $V_{0} / V$ is given by

$$
V_{0} / V=\frac{\frac{1}{R_{H}}\left(\frac{1}{R}+\frac{1}{R_{H}}\right)+\omega^{2} C_{H}\left(C+C_{H}\right)+j \omega\left(\frac{C_{H}}{R}-\frac{C}{R_{H}}\right)}{\left(\frac{1}{R}+\frac{1}{R_{H}}\right)^{2}+\omega^{2}\left(C+C_{H}\right)^{2}} .
$$

From 3 , the divider ratio is

$$
N=\frac{V}{V_{0}}=\lim _{\omega \rightarrow 0} A_{11}(\omega)=\left(R+R_{H}\right) / R
$$

This equation is the basis for the practice ${ }^{6}$ of calibrating this type of pulse divider by determining the resistance ratio.

The expression derived from the equivalent circuit indicates that $A_{11}(\omega)$ is a complex number. In general, all of the matrix elements $A_{i j}(\omega)$ are complex. Measurement systems are designed so that the ratio of the input to the output voltage can be represented as a single real number. 


\section{v}

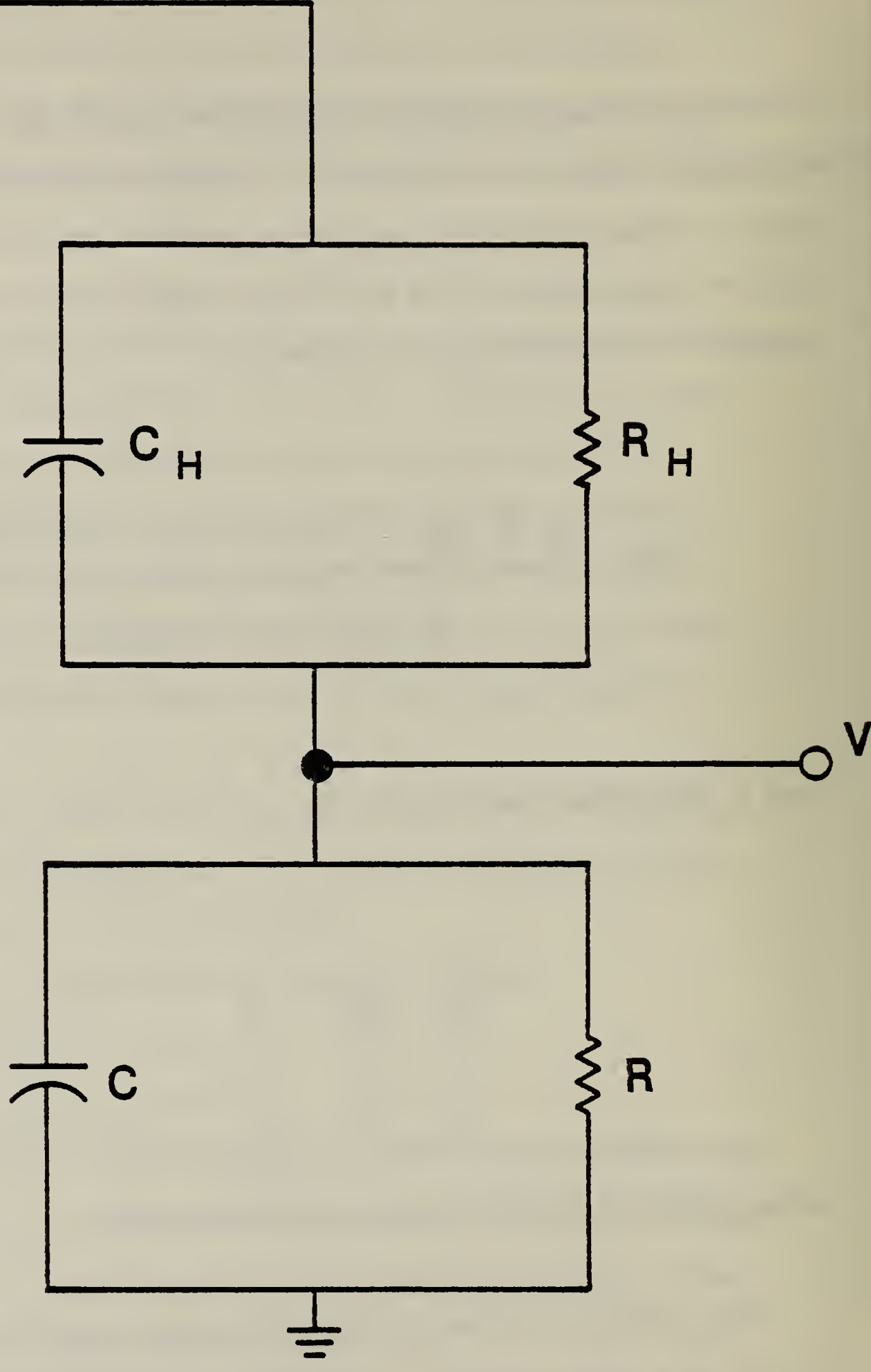

FIGURE 3.1 Approximate lumped parameter equivalent circuit for a high voltage divider. 
The divider ratio, as defined here, has that property and is the quantity which has traditionally been used in the description of dividers used to measure the voltage in diagnostic $x$-ray units. For the divider ratio to be a valid quantity, however, it is necessary that $\left|A_{11}(\omega)\right|$ not differ significantly from $N$ over the frequency range of interest. It can be seen from Eq. 4 that if

$$
R C=R_{H} C_{H} \text {, }
$$

i.e., if the divider is compensated, then $A_{11}(\omega)$ is frequency independent and the divider ratio will be real. For a variety of reasons, e.g., inadequacy of the model by not accounting for stray capacitances, construction errors, etc., the compensation in actual dividers is not exact. All dividers, therefore, have a quadrature component large enough to be measured.

Using the X-CAL system, the divider ratio [Eq. (3)] is measured by applying high voltages between $25 \mathrm{kV}$ and $75 \mathrm{kV}$. This corresponds to $x$-ray tube voltages of $50 \mathrm{kV}$ to $150 \mathrm{kV}$. The test is carried out with direct voltage so that it is also necessary to demonstrate that the divider has the appropriate frequency response. 
The frequency dependence of the ratio can be determined using the circuit shown in Fig. 3.2. The inductive voltage divider shown is a seven decade device, the division ratio of which is characterized by an uncertainty of order one part per million of the full scale reading. It should be emphasized that to measure a voltage ratio of $10^{4}: 1--a$ common ratio for dividers used with $x$-ray units--with an uncertainty of a few percent of the value of the ratio, requires that the inductive divider be accurate to a few parts per million of full scale.

Oscillator voltages are usually less than $10 \mathrm{~V}$ rms, so the output from the resistor divider is of order $10^{-3} \mathrm{~V}$. The voltmeter is a two-phase or vector instrument used in the differential input mode. Typically, the input impedance of each channel in these voltmeters is $10^{8} \Omega$ shunted by no more than $20 \mathrm{pF}$. To the measurement accuracy required, this input impedance is sufficiently large so that the measuring device causes an insignificant perturbation on the remainder of the circuit.

A two-phase voltmeter is useful because the quantity measured, $1 / A_{11}(\omega)$, is complex, i.e., Eq. 4 can be expressed in the form

$$
\frac{V_{0}}{V_{\text {in }}}=\frac{1}{A_{11}(\omega)}=\alpha+j B .
$$

If the inductive divider is adjusted so that the in-phase component of the differential voltage is zero, the value of $\alpha$ can then be read directly from the inductive divider. The magnitude of the quadrature component 


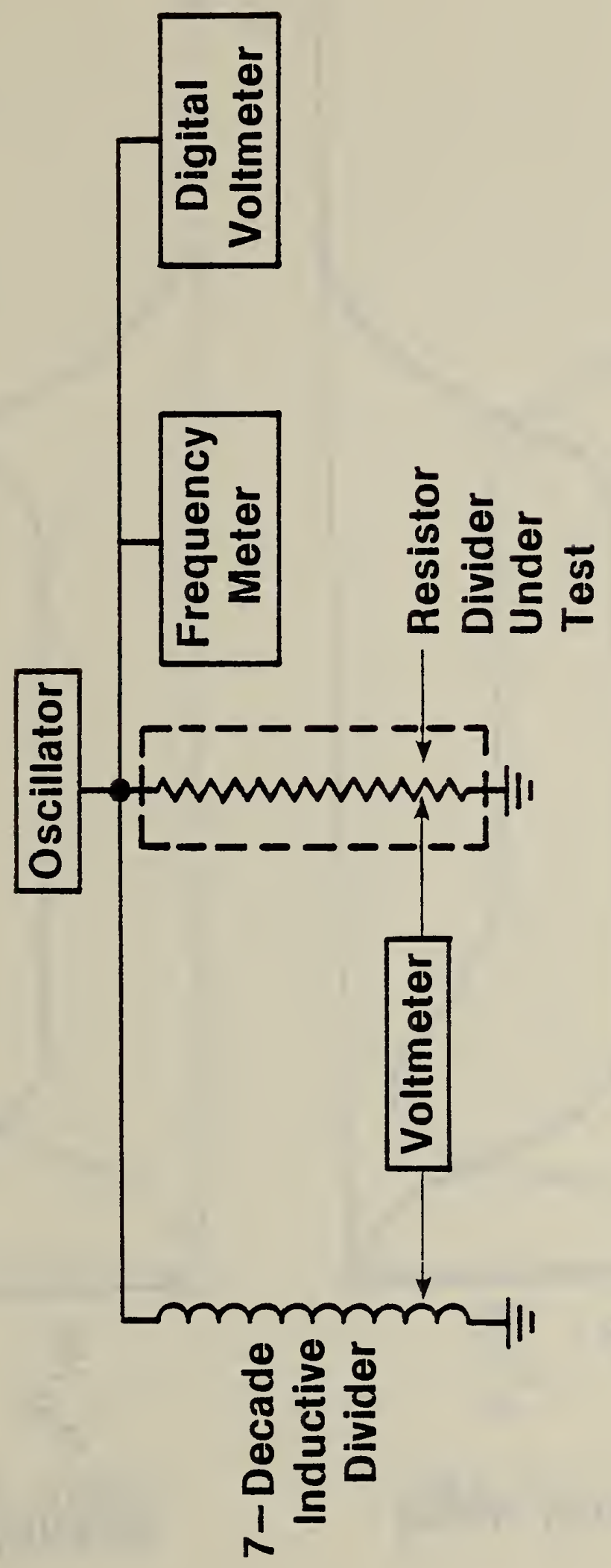


$-1 \hat{i}-$

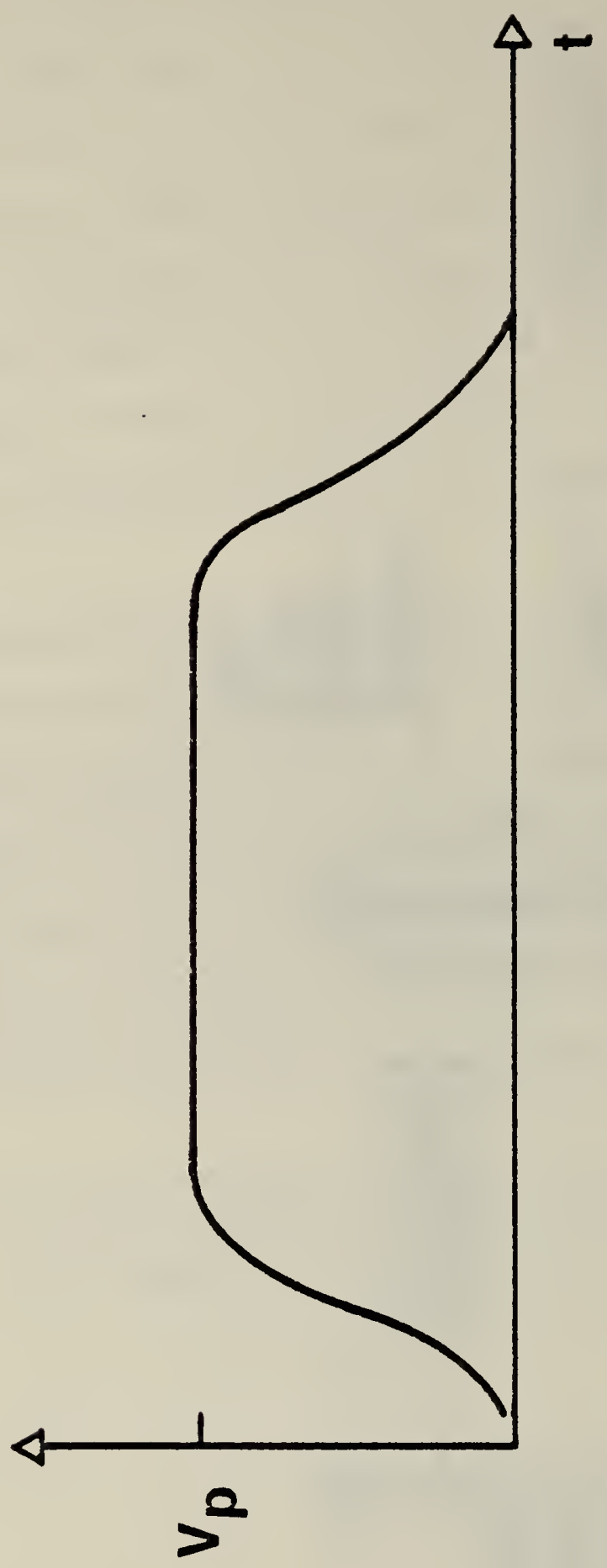

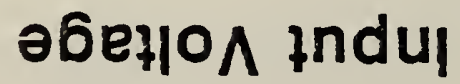

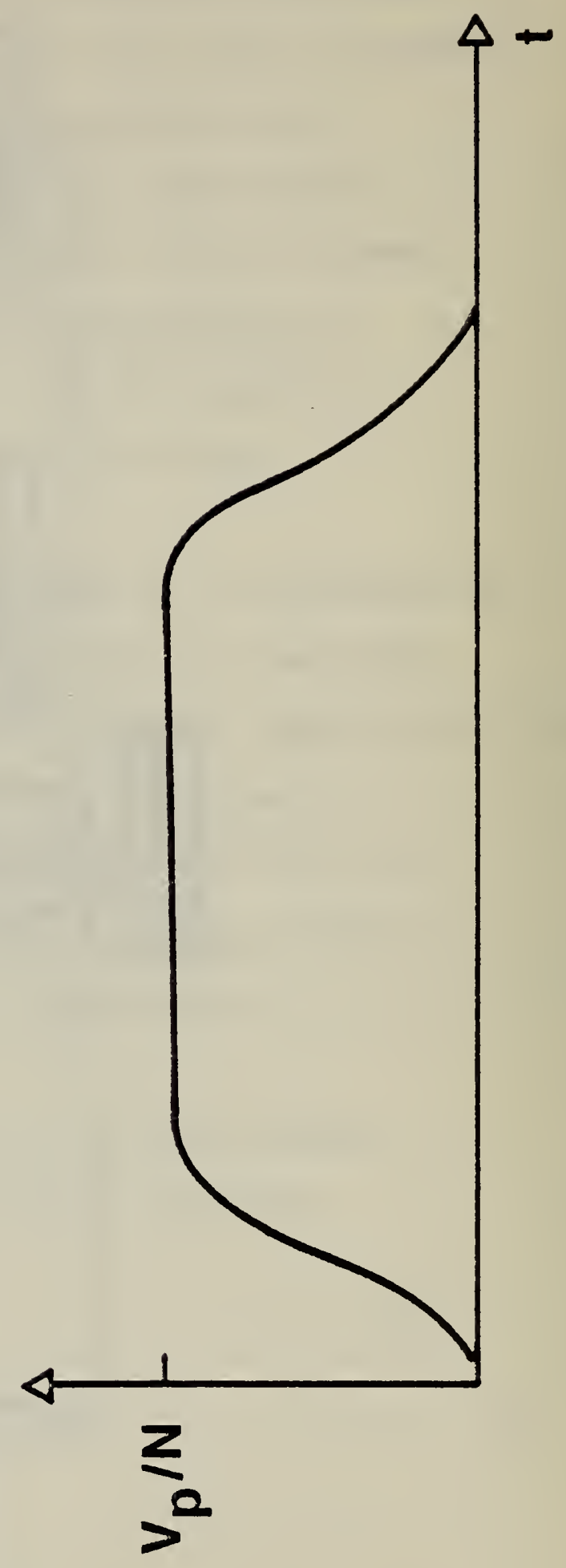

ә6eł| $\wedge$ indino 

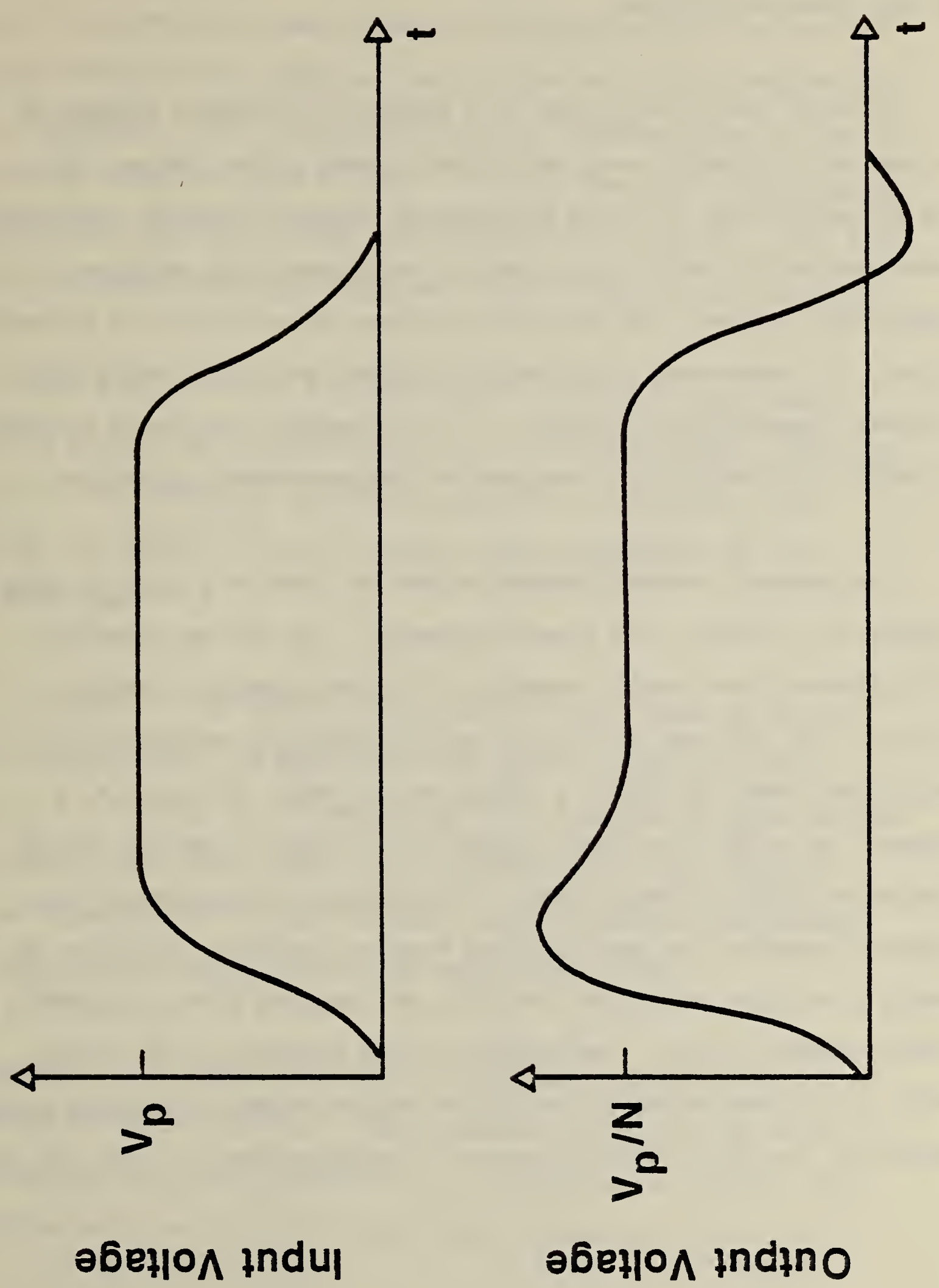

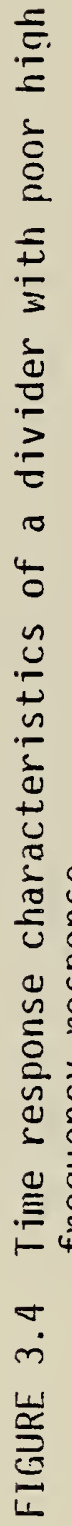

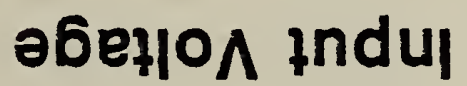

әbeł| $\Lambda$ tndino 
is read from the voltmeter.

As shown above, the voltage ratio obtained for dividers intended to be used with diagnostic $x$-ray units often depends on the frequency of the applied voltage. By using the measured frequency response, approximate measurement errors can be calculated for any assumed input waveform. It is anticipated, however, that few users would want to calculate, and mathematically correct for, measurement errors because dividers with sufficiently-small frequency dependence are available. It is, therefore, relatively convenient to obtain a divider which is designed for the measurement application.

The measured frequency dependence data can serve as a guide to judge the adequacy of a divider for a given measurement. This can be understood by considering some specific examples. The first example is shown in Fig. 3.3. In this case the voltage ratio is frequency independent and the divider output voltage is a replica of the input. In Fig. 3.4, however, the ratio of the input voltage to the output is smaller at high frequencies than at direct voltage. The magnitude and duration of the overshoot depend on the details of the frequency response. This type of waveform can cause particular difficulty when measured with an electronic peakdetect-and-hold circuit. The overshoot at the beginning of the pulse-which in this case is due to the divider and not present in the high voltage pulse--can lead to a significant error in the determination of the peak voltage. 
To avoid this difficulty, some dividers are designed so that the ratio of the input voltage to the output voltage is larger at high frequencies than at low frequencies. With this design the pulse waveforms shown in Fig. 3.5 are obtained. From the model in Fig. 1 it can be seen that this situation results if the capacitance in the low voltage arm is increased. This also leads to a non-zero quadrature component of the voltage transfer function.

In both Figs. 3.4 and 3.5 it can be seen that the divider output eventually attains its expected value, i.e., it eventually has a magnitude of $V_{p} / N$. It is, therefore, possible to obtain the true value of the $k V_{p}$ using this divider if care is taken to make measurements at the appropriate time.

By contrast, if the entire voltage pulse is short compared to the divider response time, the output would be similar to the case shown in Fig. 3.6. Although it is expected that this situation is rare, dividers with response times longer than a few milliseconds have been observed. This fact,coupled with the short exposure times available on multiphase $x$-ray units, could lead to significant measurement errors.

One final consenuence of a frequency-dependent voltage ratio is summarized in Figs. 3.7 and 3.8. These examples illustrate the results if the voltage ratio at low frequencies, e.g., $50-500 \mathrm{~Hz}$, is different from the divider ratio, which is the value of the voltage ratio under direct 
$-16-$
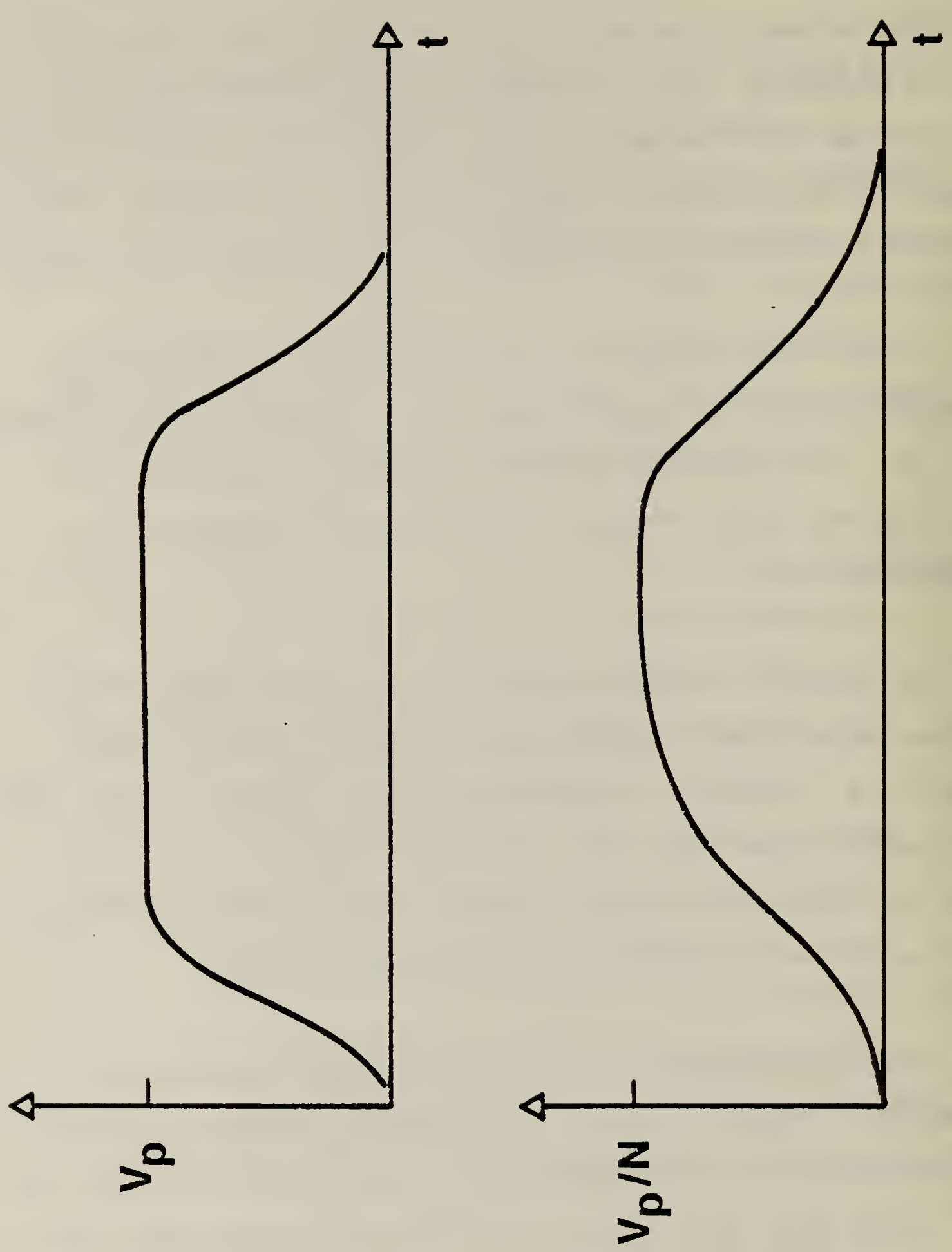

ә6อ

әбең| $\wedge$ indino 


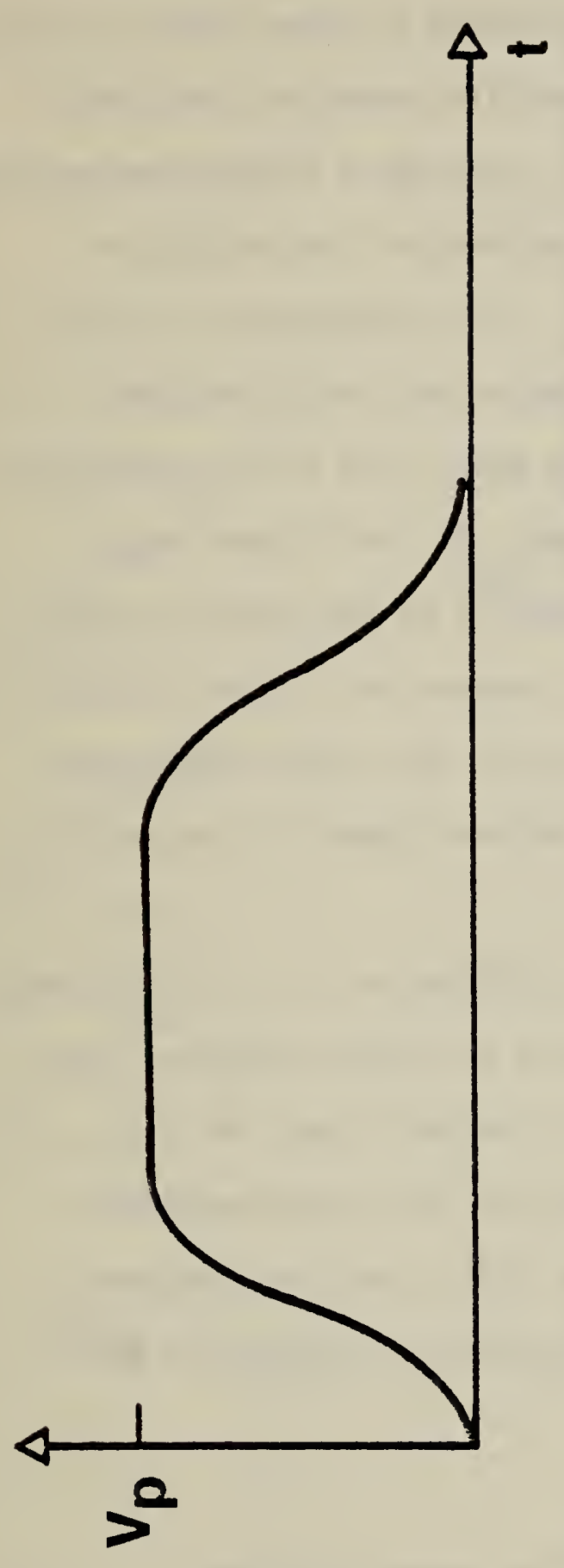

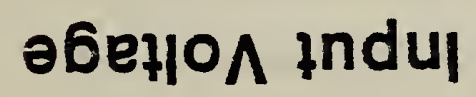

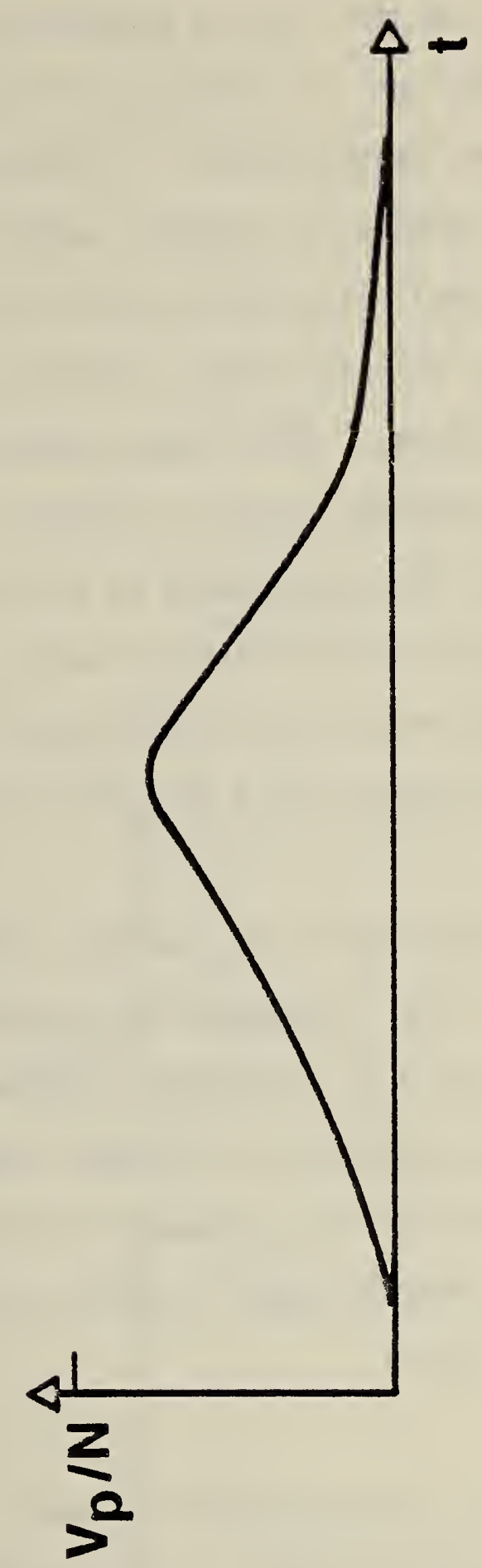

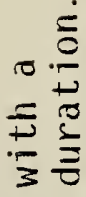

웜

$>$

的

4.

is

$\underline{y}$

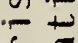

ذ广

U

送

$\stackrel{\Xi}{\mathscr{E}}$.

한

जิ

$\stackrel{d}{=}$

导

m

密 
voltage. The resulting error depends on whether the high voltage pulse applied to the $x$-ray is produced by a unit powered by three phase or single phase voltage. In the case of a three phase pulse waveform, the error could be insignificant. To illustrate this, consider a three phase waveform which can be modeled as a smooth, approximately rectangular, pulse with an added, small sinusoidal ripple (Fig. 3.7). It is assumed that the pulse duration is sufficiently long that only steady-state conditions need be considered. Under these assumptions, the peak value of the rectangular pulse component would be correctly reproduced. At the divider output, however, the ripple would be a different fraction of the peak value than it would be at the divider input. However, because the ripple is usually a small fraction of the high voltage pulse, the error in the ripple measurement may contribute only a very small error to the measurement of the pulse.

The situation is, however, substantially different for a single phase unit. If it is assumed that the waveform is a full wave rectified sine wave (Fig. 3.8), elementary Fourier analysis indicates that the low frequency components contribute significantly to the voltage waveform. Therefore, if it is assumed that the divider ratio, which is measured under direct voltage, is valid in this application, a substantial error could result.

The current through the tube is pulsed and roughly follows the voltage waveform. A traditional measurement technique is to apply the pulsed current to a resistor and measure the voltage drop across 

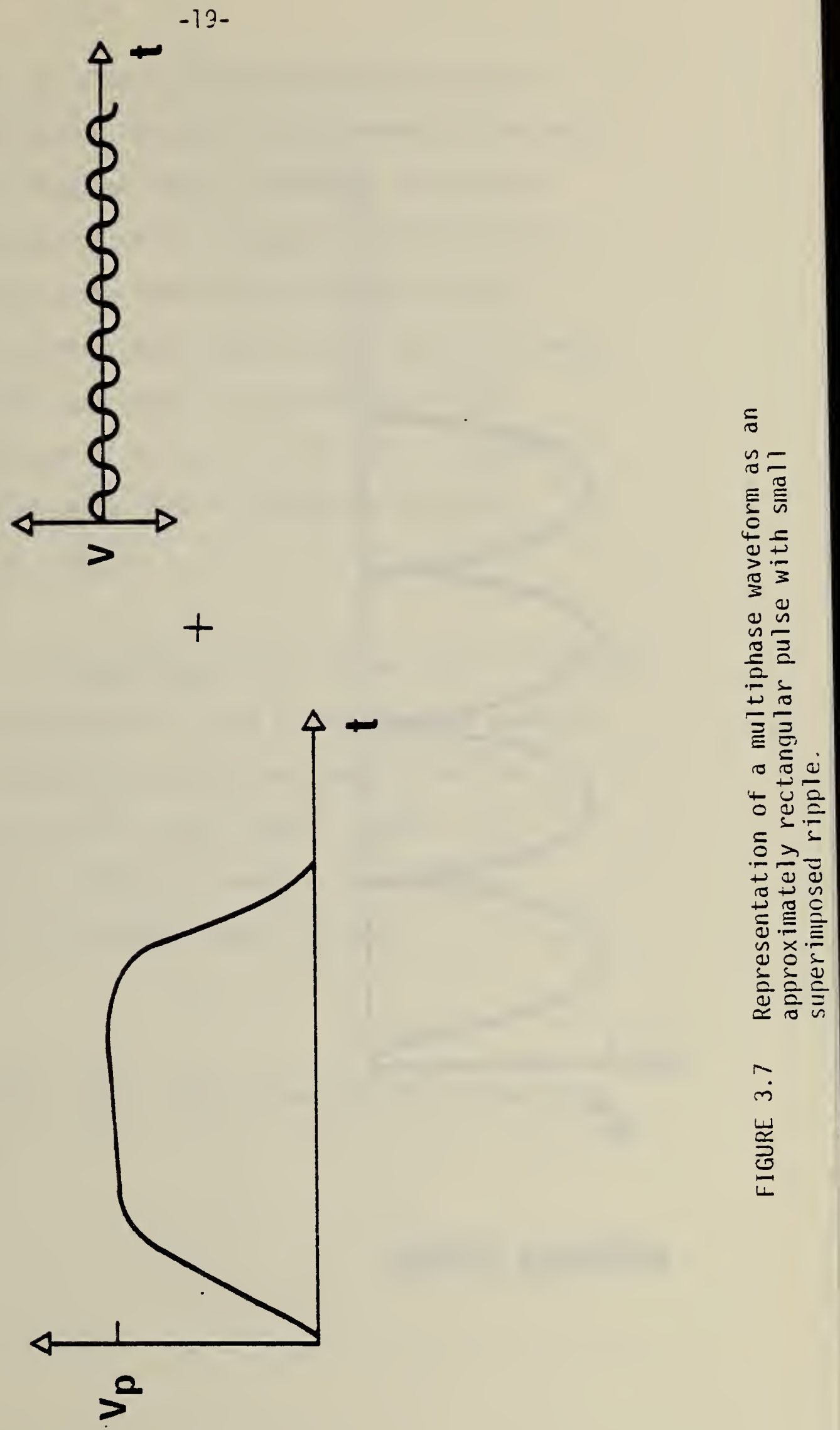

n
$\frac{U}{2}$
$\frac{1}{4}$ 


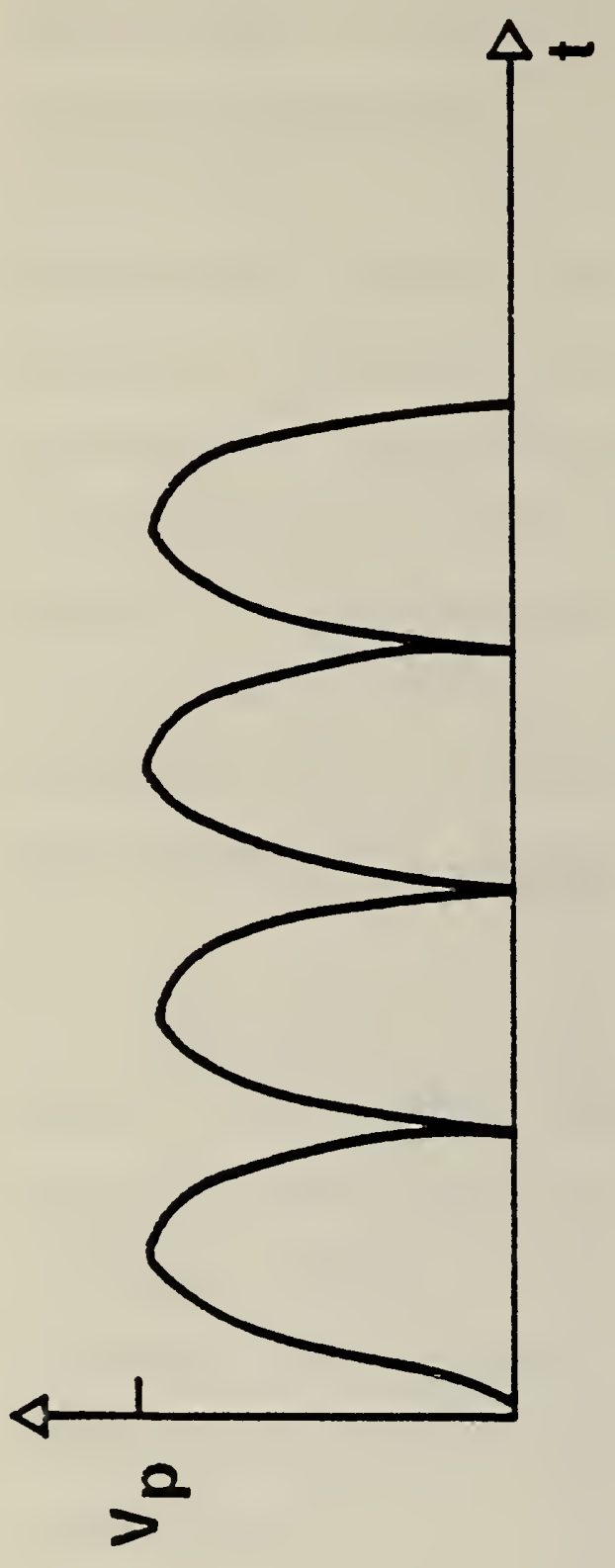

ә6e)|O indu|

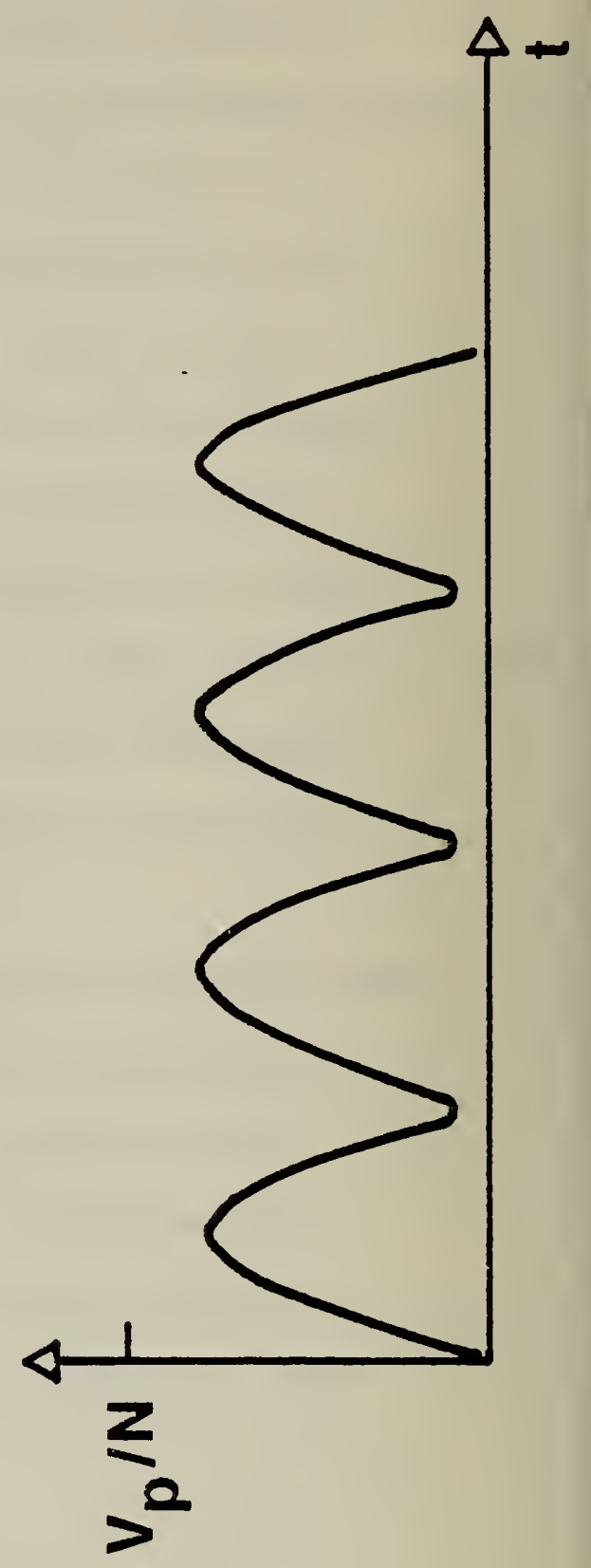

әbello $\wedge$ indino 
the resistor. That technique was chosen in this application because the impedance of the current-viewing resistor is independent of frequency to the accuracy, and over the frequency ranae, renuired. The voltage across this resistor is monitored using a peak-detect-and-hold circuit so the measuring circuit displays the magnitude of the peak current. The circuit is designed to calibrate measurement systems having an input impedance of approximately $200 \Omega$ and which do not require that the current-carrying line be grounded to the device under test. A possible modification of the X-CAL which would permit calibration of pulse transformers is suggested in Section 6 .

The filament current is a steady-state, $60-\mathrm{Hz}$ current with a magnitude up to $20 \mathrm{~A}$. The measurement approach is to use a very accurate current transformer having a well-characterized resistive burden to provide a voltage signal which is proportional to the filament current. This voltage is then measured using a digital voltmeter. The system is designed to display the rms value of the filament current.

\section{System Description}

4.1 The X-CAL calibration system allows five specific calibrations to be performed. These are: 
4.1.1 Direct Voltage Divider Ratio Calibration

4.1.2 Alternating Voltage Divider Ratio Calibration

4. 1.3 Frequency Dependence of the Divider Ratio

4.1.4 Filament Current

4.1.5 Anode Current.

Each of these functions is discussed in more detail in the following sections.

\subsection{Direct Voltage Divider Ratio Calibration}

The electrical system used in this calibration is illustrated schematically in Fig. 4.1. A direct voltage, variable from 0 to $\pm 75 \mathrm{kV}$, is applied to a Park divider ${ }^{14}$ and to the device under test. The low side of the Park divider is active as indicated in Fig. 4.1. The active low side configuration offers a significant advantage over passive low sides in that deleterious effects such as loading due to the indicating instrument are virtually eliminated. In this configuration, the voltages indicated by the calibration system and the device under test may be compared directly if the device under test has a self-contained readout capability. If not, the calibration unit contains a low side system which may be operated in either a passive or active mode to provide a digital display of the output voltage from the device under test.

\subsection{Alternating Voltage Divider Ratio Calibration}

The measurement technique employed in this calibration is shown in Fig. 4.2. The ac power supply (provided by user) applies an alternating 

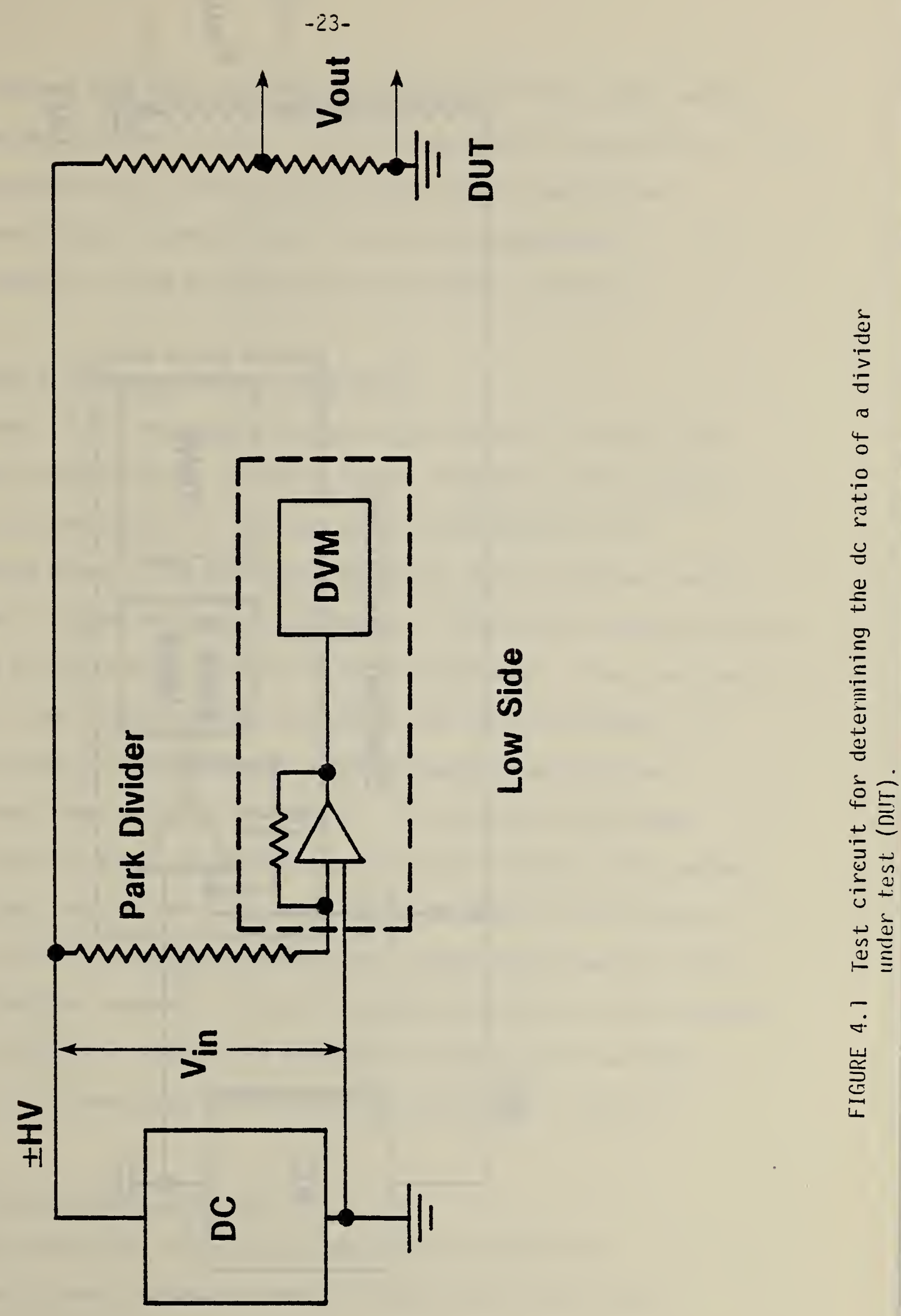


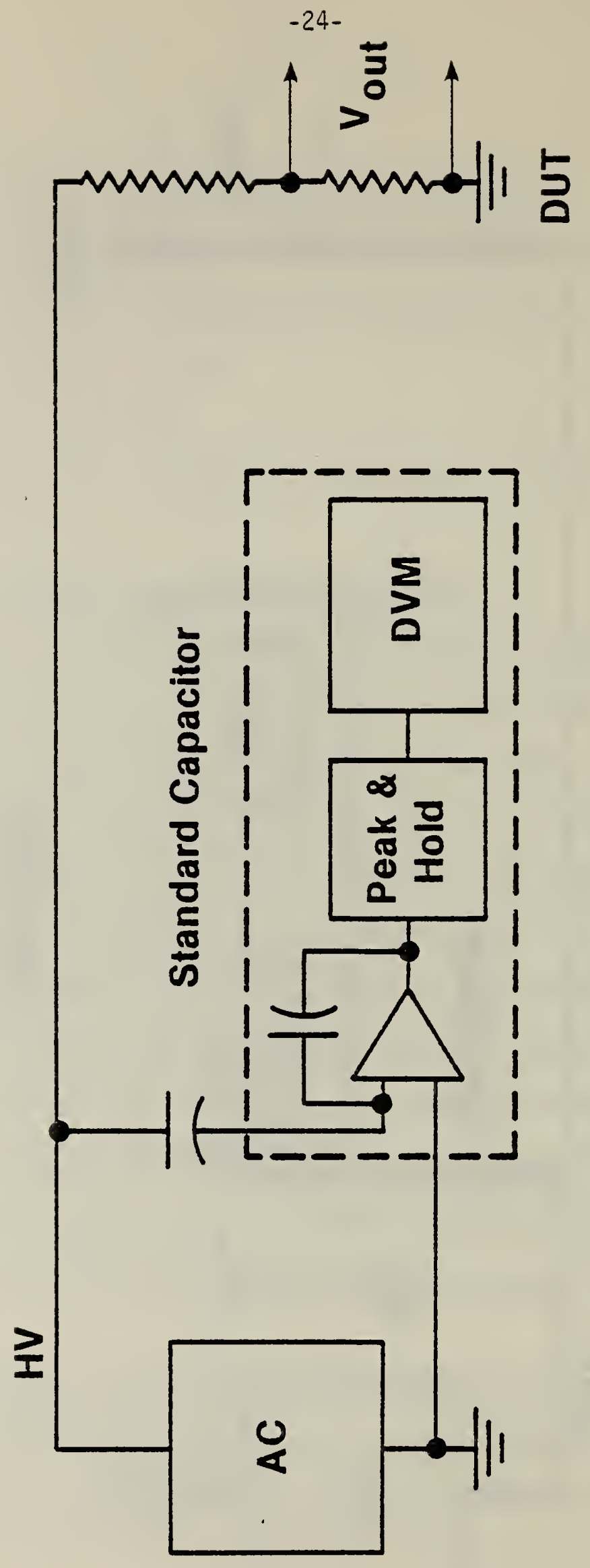


voltage to a standard capacitor (provided as part of the X-CAL system) which again incorporates an active low side. In this measurement, the low side voltage is introduced into a peak and hold circuit, which acquires and holds the maximum voltage impressed upon it during the measurement period. This voltage is read and displayed by a digital voltmeter.

\subsection{Frequency Response of the Divider Ratio}

A measurement of the frequency response of the divider ratio over the frequency range $50-10,000 \mathrm{~Hz}$ can provide a direct indication of the physical condition of a divider and can be used to predict the response of the divider to voltage pulses. The electrical schematic of the technique used in this measurement is shown in Fig. 4.3. A source of alternating voltage provides a signal to the device under test and to a ratio transformer. A well-defined fraction of the input voltage may be selected by the ratio transformer. A phase sensitive detector, operated as a vector voltmeter, measures the difference between input voltages "A" and "B". If the ratio transformer is adjusted to provide a null indication on the vector voltmeter, the reading of the ratio transformer is equal to the in-phase component of the divider ratio. There will also be a quadrature voltage, since the divider has both resistive and reactive components, and this quadrature voltage is read directly from the vector voltmeter. These readings may be combined with the input voltage to provide a normalized divider ratio as described in Section 6 .

\subsection{Filament Current Calibration}

The Machlett Dynalyzer ${ }^{1}$ provides the user with the capability of measuring the filament current of the $x$-ray tube in the $x$-ray unit 
$-26-$

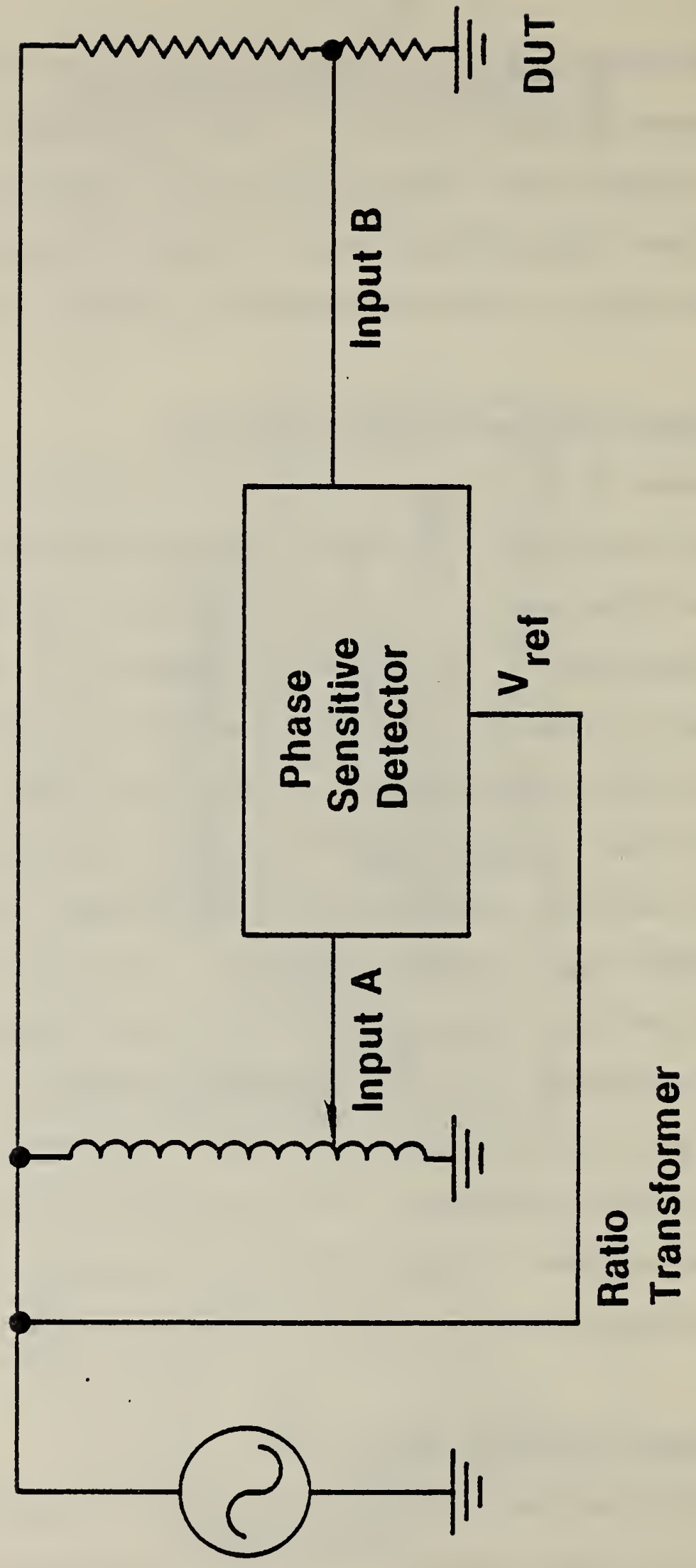


under test. The X-CAL system may be used to calibrate the filament current measuring system as is indicated in Fig. 4.4. An alternating current, variable between 0 and 20 amperes, passes through a current viewing resistor (nominally $1 \Omega$ ). The current value measured by the commercial system can be compared to that determined by the precision instrument current transformer which is a part of the X-CAL unit.

\subsection{Anode Current Measurement Calibration}

The $\mathrm{X}$-CAL system provides a current pulse (variable up to 2 amperes) which may be used to calibrate a Machlett Dynalyzer ${ }^{1}$ unit as illustrated in Fig. 4.5. The pulse generator, when triggered, drives current through the nominal 200-ohm load of the device under test. The current waveform, which is not intended to duplicate an actual $x$-ray machine current pulse, is approximately rectangular. There is some droop to the pulse with the maximum current occurring immediately after triggering. The maximum value of the current is determined by amplifying the voltage drop across a current viewing resistor (CVR) and applying this voltage to a peak and hold circuit which captures the maximum voltage level (corresponding to maximum current). The commercial unit measures the average value of the current pulse so a conversion factor relating the peak current value and the average current has been determined for the pulser in the X-CAL unit driving the nominal 2 no ohm load of Machlett Dynalyzer ${ }^{1}$ to allow direct comparison of the two readings.

\section{Installation}

The X-CAL system consists of two enclosed racks of electric instruments, connecting cables and a standard capacitor. A necessary component of the system is a Park resistor, which is to be provided by the user. 


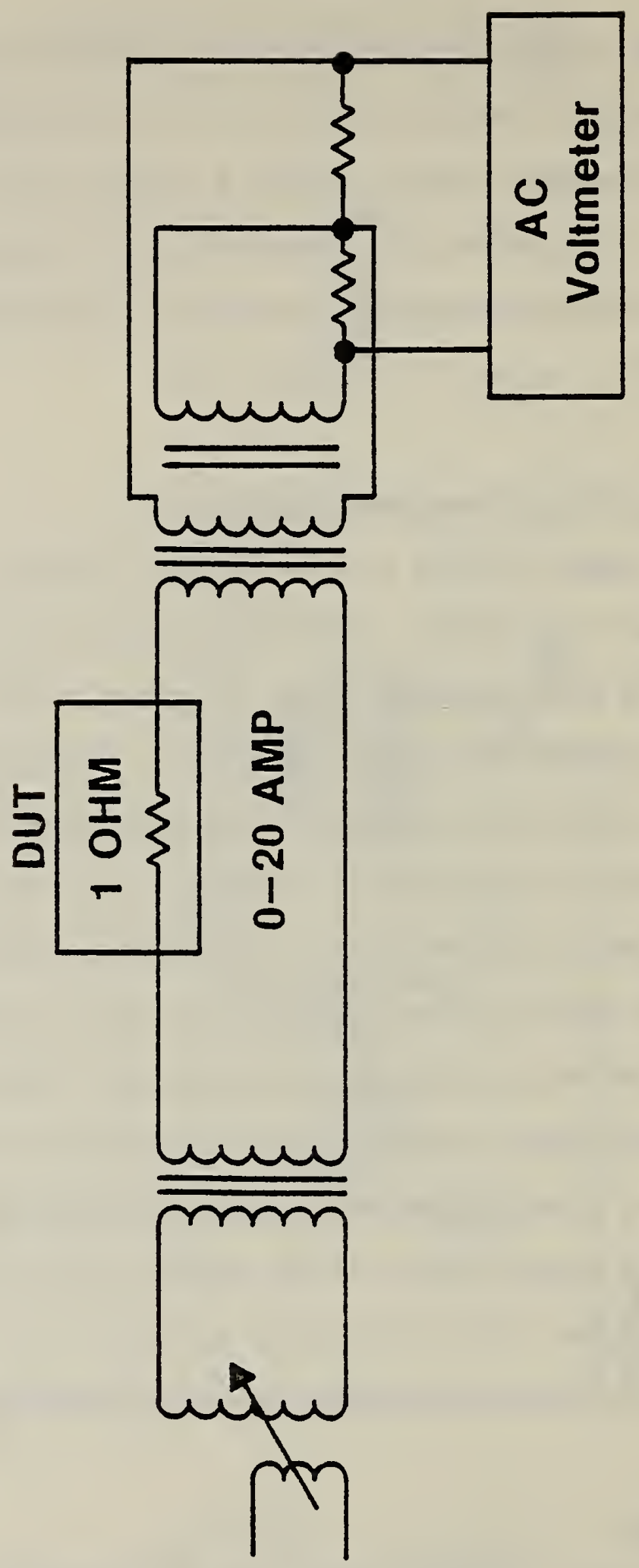




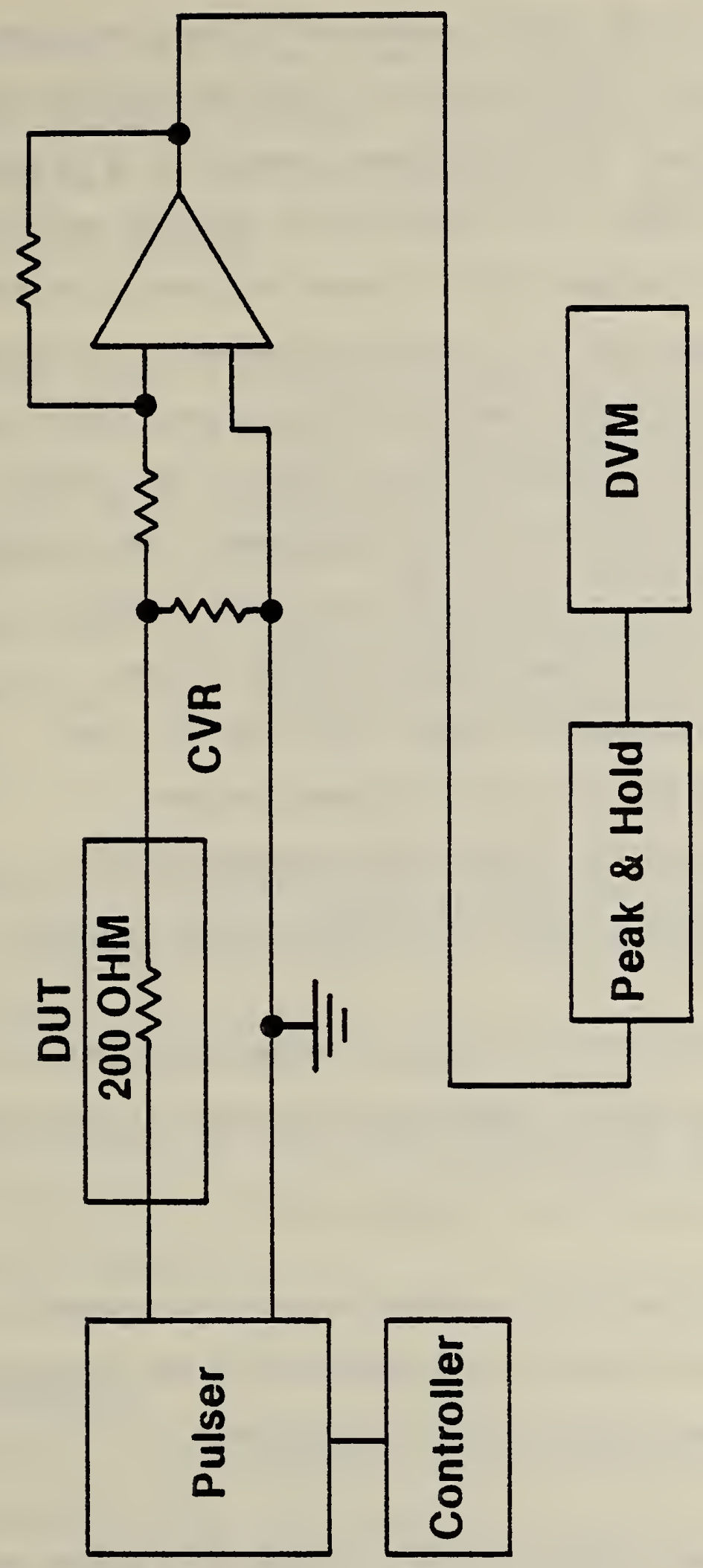

造

$\stackrel{\mathscr{\Delta}}{\square}$

Ð

苂

ऐे जे

竞

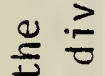

욜

जी

$\stackrel{0}{0}$

$\tilde{\sigma}$

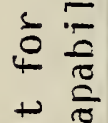

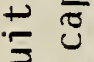

ड

0

$\omega$ जे

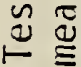

$\stackrel{8}{\circ}$

$\leftarrow$

岕 
Upon receipt of the system, uncrate all cartons and inspect the contents for damage. The high-voltage transformer assembly should be removed from its case. This transformer assembly is to be mounted in the high voltage cabinet. This installation should be such that the outlet for the high voltage cable is toward the rear of the cabinet. Be careful not to damage the $x$-ray connectors located on the front panels of the high voltage cabinet when installing the transformer assembly. After the transformer assembly has been placed in the cabinet, it should be filled with oil according to the manufacturer's specifications.

CAUTION: Avoid introducing any foreign material into the transformer assembly during filling. When the assembly has been filled with oil, the high voltage cable may be inserted and then connected to the corona shield attached to the $x$-ray connector used for the high voltage dc tests.

The main electronics rack should be inspected to make sure that all cables are in place and all plugs securely inserted in their corresponding sockets.

Coaxial cables should be connected between the appropriate input and output terminals of the ratio transformer and the corresponding bulkhead feedthrough mounted on the bulkhead panel.

The high voltage cabinet should be located in a secure area in accordance with the users' safety regulations. Interconnecting cables allow approximately $7 \mathrm{~m}$ between the main cabinet and the high voltage cabinet. 
Output cables (anode and cathode) should be connected to the corresponding input and output connectors. The HV-interlock cable and the control cable between the high voltage control unit and the transformer assembly should also be connected.

A good grounding system is necessary to insure proper system operation as well as for safety reasons. A ground strap should be run to the grounding terminal on the transformer assembly, the high voltage cabinet and between the two cabinets. In addition, the ground terminals on the high voltage control unit and the current pulser should be connected to the rack ground which is then attached to a reliable ground in the users laboratory.

The best technique for ascertaining that the system is functioning . properly is to calibrate an x-ray divider unit. Detailed operating instructions are given in Section 6 .

Conditioning procedures for the dc high voltage supply are given by the manufacturer and should be followed whenever the high voltage tank is drained and refilled with oil.

\section{Operating Instructions}

6.1 The following sections describe in detail how the measurements leading to the calibration of an x-ray divider are to be done. In each case, the user should become more adept at making measurements as he gains experience. Local operating procedures may be generated, providing the integrity of the measurements are not compromised. Local safety rules regarding high voltages should be followed. The high voltage supply 
provided with the system generates lethal voltage and current levels and should be treated accordingly. Cables connecting $x$-ray dividers to the high voltage cabinet may retain considerable charge after high voltage tests are completed and the judicious use of a grounding stick is highly recommended.

\subsection{Dividers with Display Units}

The instructions in the following sections assume the divider under test is one which has a display unit as an integral part of the system. For dividers not meeting this requirement, refer to section 6.8.

\subsection{High Voltage (DC) Divider Ratio}

The test configuration is shown in Fig. 6.1. The high voltage cable is connected to the device under test (either anode or cathode) and then passed through the divider unit to a Park divider. It should be noted that $x$-ray divider units are designed to be inserted between the $x$-ray machine power supply (transformer) and the $x$-ray tube itself. The high voltage divider assembly (shown as a resistor divider in Figs. 4.1-4.3) is connected internally to the high voltage cable. All high voltage connections are made by using standard $x$-ray high voltage cables and connectors which results in a configuration with no exposed high voltage. In Fig. 6.1 and following figures in this section, connections involving high voltage cables are shown symbolically as originating from the top of the divider unit under test. The measurement mode should be set to DCHV and the output from the Park resistor connected to PARK on the input bulkhead panel. With the system turned on and allowed to stabilize for 15-20 minutes, a reading of zero $( \pm 1-2 \mathrm{mV})$ should be observed on the digital readout on "x-ray". The high voltage polarity appropriate for the 


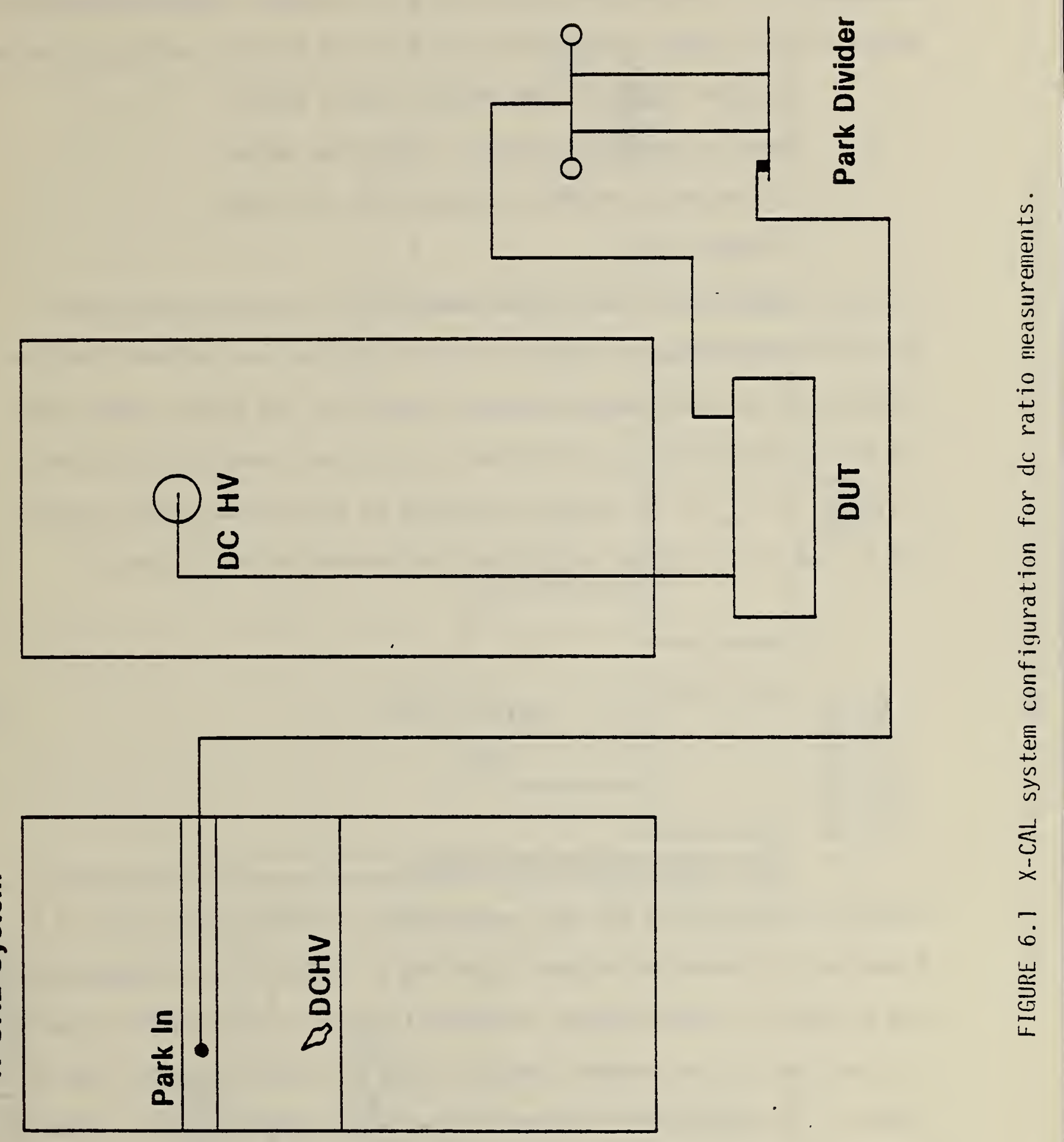


test should be selected. Measurements over the desired range may now be made. Reconnection of the high voltage leads and a change in high voltage supply polarity is all that is required to go from one divider section to another.

CAUTION: OBSERVE HIGH VOLTAGE SAFETY RULES!

Refer to the manufacturers instruction manual

for proper operating procedures for the high voltage supply.

A direct comparison of the voltage recorded by the device under test and the input voltage as given by the Park divider may be made from the readings of the individual displays of the X-CAL and device under test. The X-CAL system has been calibrated to be direct reading with a Park divider. If $V_{\text {in }}$ is the voltage indicated by the standard Park divider and $V_{x}$ the $x$-ray divider indication, the divider ratio is given by

$$
\text { Ratio }=\frac{V_{\text {in }}}{V_{x}}
$$

6.4 High Voltage (AC) Divider Ratio

The test configuration for this measurement is shown in Fig. 6.2. A source of alternating voltage (supplied by the user) is connected to the divider in a pass-through configuration and to the standard capacitor. The low side of the standard capacitor goes to the CAP input of the X-CAL system. The measurement function on the X-CAL system is ACHV. Pressing the reset button on the ma in chassis reduces the X-CAL readout to zero and enables the peak and hold circuit. When the ac supply is activated, either in a continuous or pulsed mode, the peak and hold circuit will 


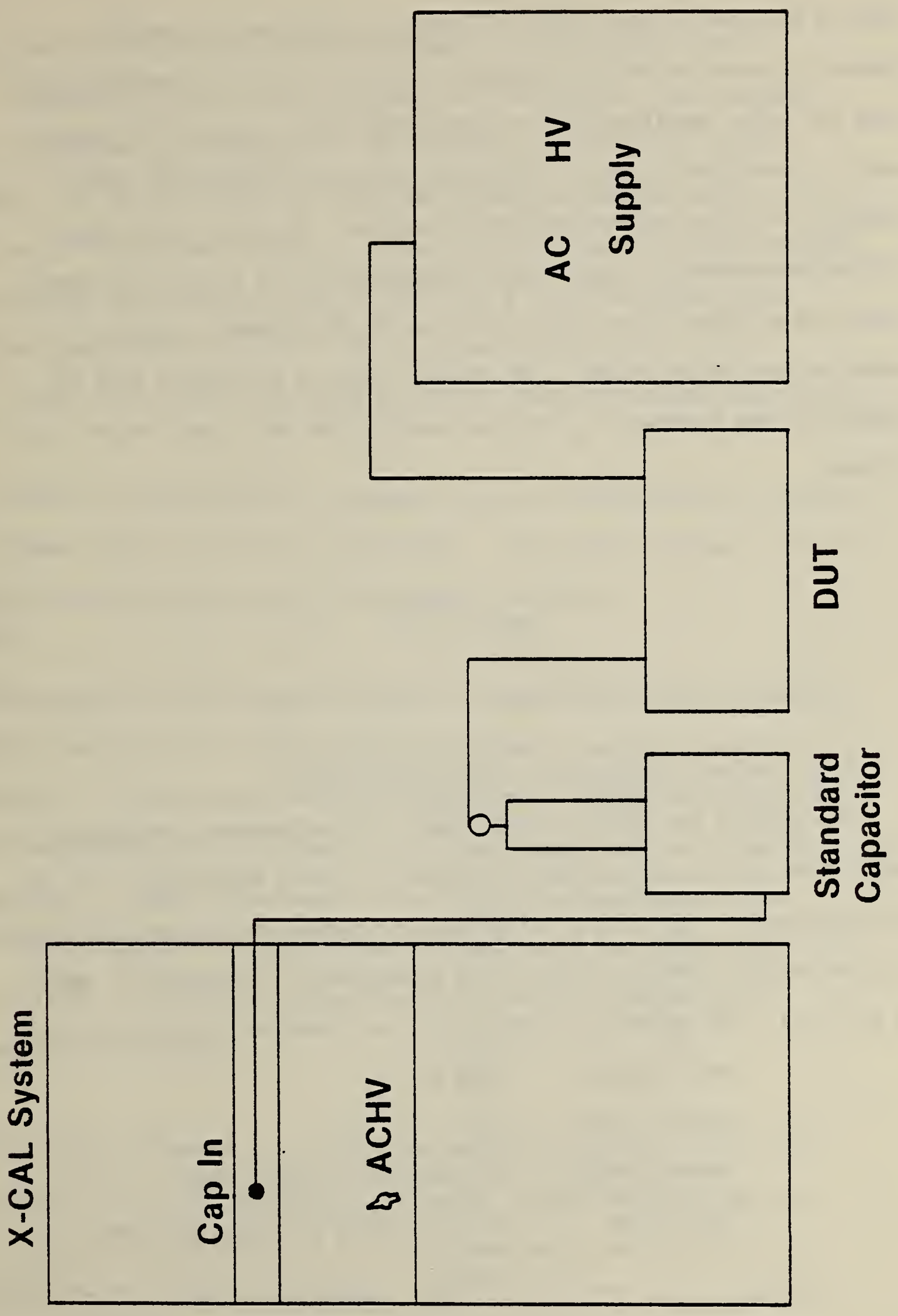

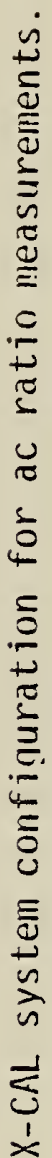

$\checkmark$

崩 
acquire the peak voltage which will then be displayed on the DPM. Because of droop in the peak and hold circuit, it will be necessary to read the meter immediately after energizing the ac supply if a pulsed mode of operation is used. The system has been calibrated to read directly with the standard capacitor supplied. As with the dc high voltage measurement, proper safety procedures should be followed when using the ac supply. Make sure the case of the standard capacitor is connected to system ground. The divider ratio is calculated from the reading of the standard $V_{i n}$ and the reading from the $x$-ray divider $V_{x}$ as follows

$$
\text { Ratio }=\frac{V_{\text {in }}}{V_{x}} \text {. }
$$

\subsection{Frequency Dependence of the Divider Ratio}

The purpose for making a measurement of the frequency response of the divider has been discussed in Section 3. These measurements are the most involved of the various calibration procedures but become straightforward with increasing user experience. The experimental arrangement is shown in Fig. 6.3. The switches on the control unit should be set as follows:

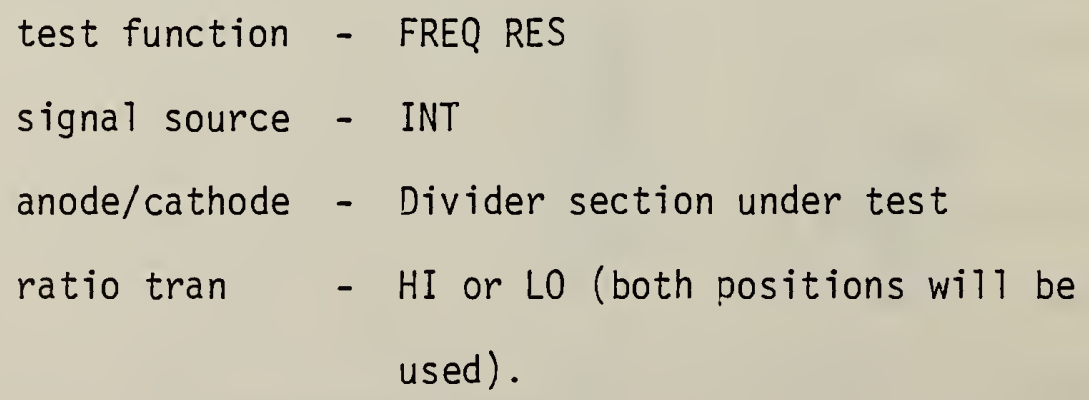


A coaxial cable may be connected between the front panel "ref" coaxial connector on the vector voltmeter and the input of the frequency counter if the exact frequencies of the internal oscillator are to be recorded. The function generator provides a continuously variable signal and if this signal source is to be used, the signal source selector on the control unit should be set to "EXT" and a cable connected from the signal generator to the "EXT" input on the feedthru panel. The output level of the signal generator should be adjusted to approximately $5 \mathrm{~V}$ rms.

A digital voltmeter with ac response flat to $10 \mathrm{kHz}$ should be connected to the chosen input of the ratio transformer. The $0.35 \mathrm{f}$ section is the "HI" frequency section and $2.5 \mathrm{f}$ the "LO" frequency section.

The operation of the vector voltmeter is summarized in this section. This device measures the voltage difference between two input signals "A" and "B". If the divider and ratio transformers were purely resistive, then all voltages and currents would be in phase and a simple voltmeter would suffice. Indeed, there would be no frequency dependence of the ratio. This, however, is not the case and because of the stray capacitance in the divider, there will be some relative phase shift between the voltages in the circuits.

The vector voltmeter is initially adjusted so that one of the input signals, say "A", is in phase with a reference signal derived from the signal source. When operated in the difference mode, the difference of the two inputs "A" - "B" is displayed. Since "A" and "B" are in general not in phase, their difference is determined in terms of two components. One is in phase with "A", and the other in quadrature. 


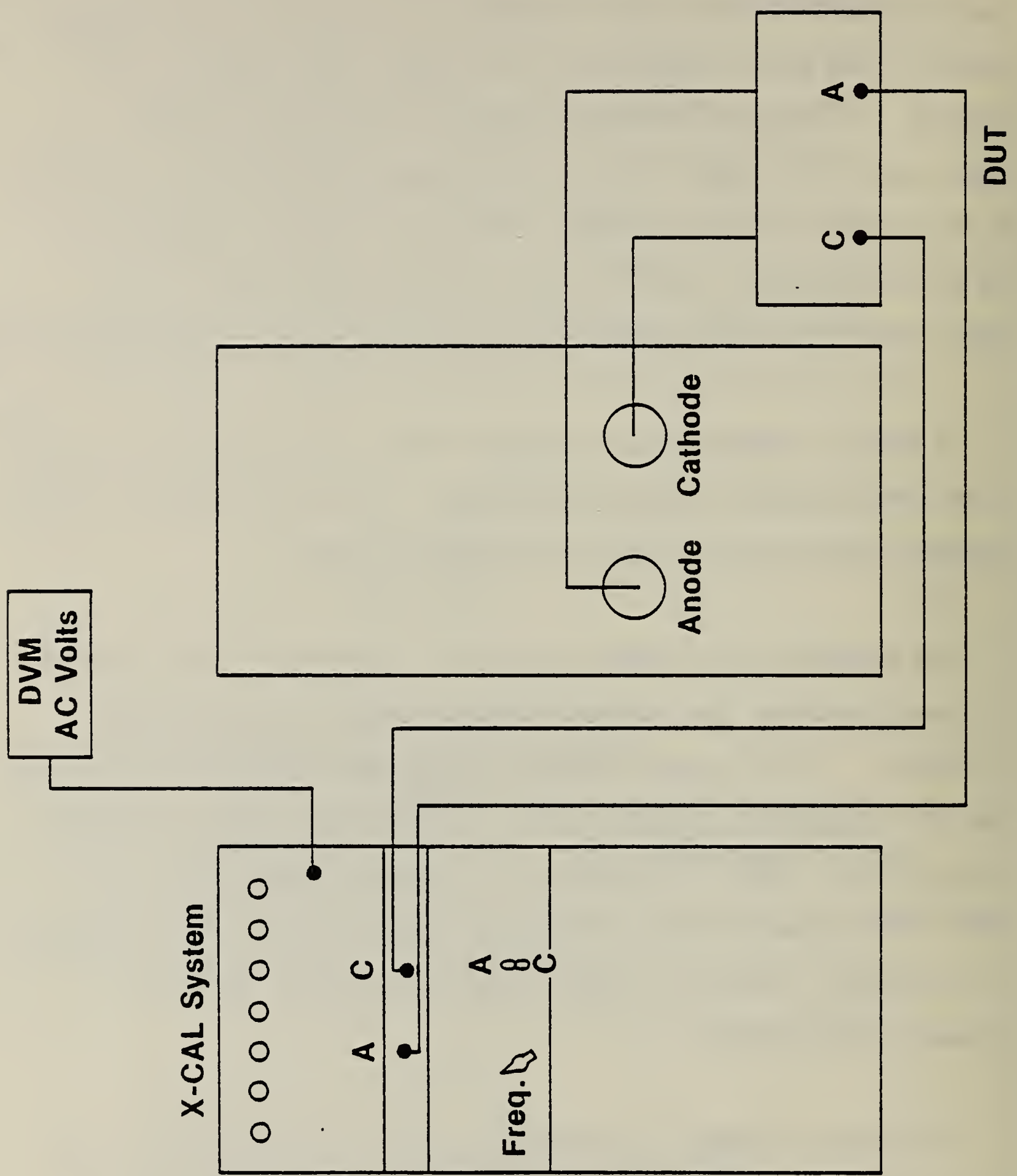


After the initial adjustment of phase, the ratio transformer is varied until the in phase component of "A" - "B" is zero. At this point, the measurement of the ratio for a given frequency is complete. The quantity a defined in Section 3 is the reading of the ratio transformer. The quantity $\beta$ also defined in Section 3 is just the ratio of the quadrature voltage $V_{\text {quad }}$ to the input voltage determined by the DVM, $V_{\text {in }}$;

$$
\beta=\frac{V_{\text {guad }}}{V_{\text {in }}} \text {. }
$$

It should be noted that there are corrections to be made to the $\alpha$ and $\beta$ values for $5-$ and $10-\mathrm{kHz}$ signals. These corrections are for the ratio transformer and are of the order of $3 \%$ for the $10-\mathrm{kHz}$ ratios. The additive corrections $d \alpha$ and $d \beta$ which are taken from the data sheet supplied for the ratio transform should be applied to the uncorrected values $\alpha$ and $\beta$ obtained according to the procedure described above. The divider ratio may then be simply calculated as

$$
\text { Ratio }=\frac{1}{\sqrt{\alpha^{2}+\beta^{2}}}=\frac{v_{\text {in }}}{v_{\text {out }}} \text {. }
$$

The initial adjustment of the vector voltmeter is done in the following way. The initial control positions on the vector voltmeter are: 


\section{SIGNAL}

Input Mode

Flat

Float

A

Sensitivity

$\begin{array}{ll}\text { - } & 100 \mathrm{mV} \\ \text { - } & \text { Switches out } \\ \text { Switches out }\end{array}$

Reference

Phase

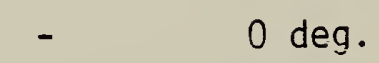

Mode

- $\quad f$

ext

\section{In Phase}

$\begin{array}{lll}\text { Zero Offset } & - & 0.0 \\ \text { Time Constant } & - & 0.1 \mathrm{~Hz} \\ \text { Output Expand } & - & \times 1 \\ \text { Prefilter } & - & 0.15 \mathrm{~s}\end{array}$

Quadrature

Zero Offset

0

Time Constant

$0.1 \mathrm{~Hz}$

Output Expand

$\times 7$

Prefilter

$0.1 \mathrm{~s}$

Outputs

in - phase

Quad 
The ratio transformer should be set to 0.0001 (for a $10^{4}$ to 1 divider). At this point both the in phase and quadrature meters should deflect. The phase control should be adjusted to make the quadrature reading zero. The "full scale sensitivity" and the "output expand" switches for the quadrature component can be changed to give an extremely sensitive indication of proper adjustment. For the $50-\mathrm{Hz}$ measurement, some "beating" between the $50-\mathrm{Hz}$ signal and the ac 1 ine frequency $(60 \mathrm{~Hz})$ may be present as evidenced by an oscillation of both the in-phase and the quadrature meters. The user should adjust the instrument so that the indicator excursions are centered on zero.

The $A, A-B$ switch should now be placed in the $A-B$ position. Again, both in-phase and quadrature indicators should deflect. Now, the ratio transformer, should be adjusted to make the in-phase reading zero. This can be done very precisely by increasing meter sensitivity during the nulling adjustments. When this process is complete, the ratio transformer setting and the quadrature voltage should be recorded. Now, the frequency may be changed, the initial adjustments made and the measurement process repeated.

A complete set of measurements should be done using both the $0.35 \mathrm{f}$ and $2.5 \mathrm{f}$ sections of the ratio transformer. The mid-frequency measurements for both sections should be the same. The $50-\mathrm{Hz}$ value should be taken from the $2.5 \mathrm{f}$ data and 211 others from the $0.35 \mathrm{f}$ data. A useful presentation of the results of the frequency response measurement may be obtained by normalizing the frequency dependent ratio to the dc ratio measured at low voltages $(\sim 500 \mathrm{~V})$. 


\subsection{Filament Current}

The Machlett Dynalyzer ${ }^{1}$ indicates the filament current flowing to the $x$-ray tube by measuring the voltage across a 1 -ohm current viewing resistor. When the X-CAL system is configured as indicated in Fig. 6.4, this current reading may be compared to that obtained in the X-CAL system from a precision current transformer. The current may be adjusted up to 20 amperes and readings compared directly. In this measurement, the function switch should be in the "fil I" position.

CAUTION: Do not enable the anode current pulser when the system is configured for cathode testing. Damage to the DUT could result if the pulser used for anode current testing is discharged through the filament current viewing resistor.

\subsection{Anode Current}

The anode current in an $x$-ray tube is normally pulsed and the X-CAL system contains a dc pulser to provide a rectangular pulse which provides peak currents from 0.05 amp to 2 amp. The function switch should be in the "anode I" position and the system connected as shown in Fig. 6.5.

CAUTION: Do not enable the anode current

pulser when the system is configured

for cathode testing. Damage to the DIJT

could result if the pulser used for

anode current testing is discharged through

the filament current viewing resistor. 
$-43-$
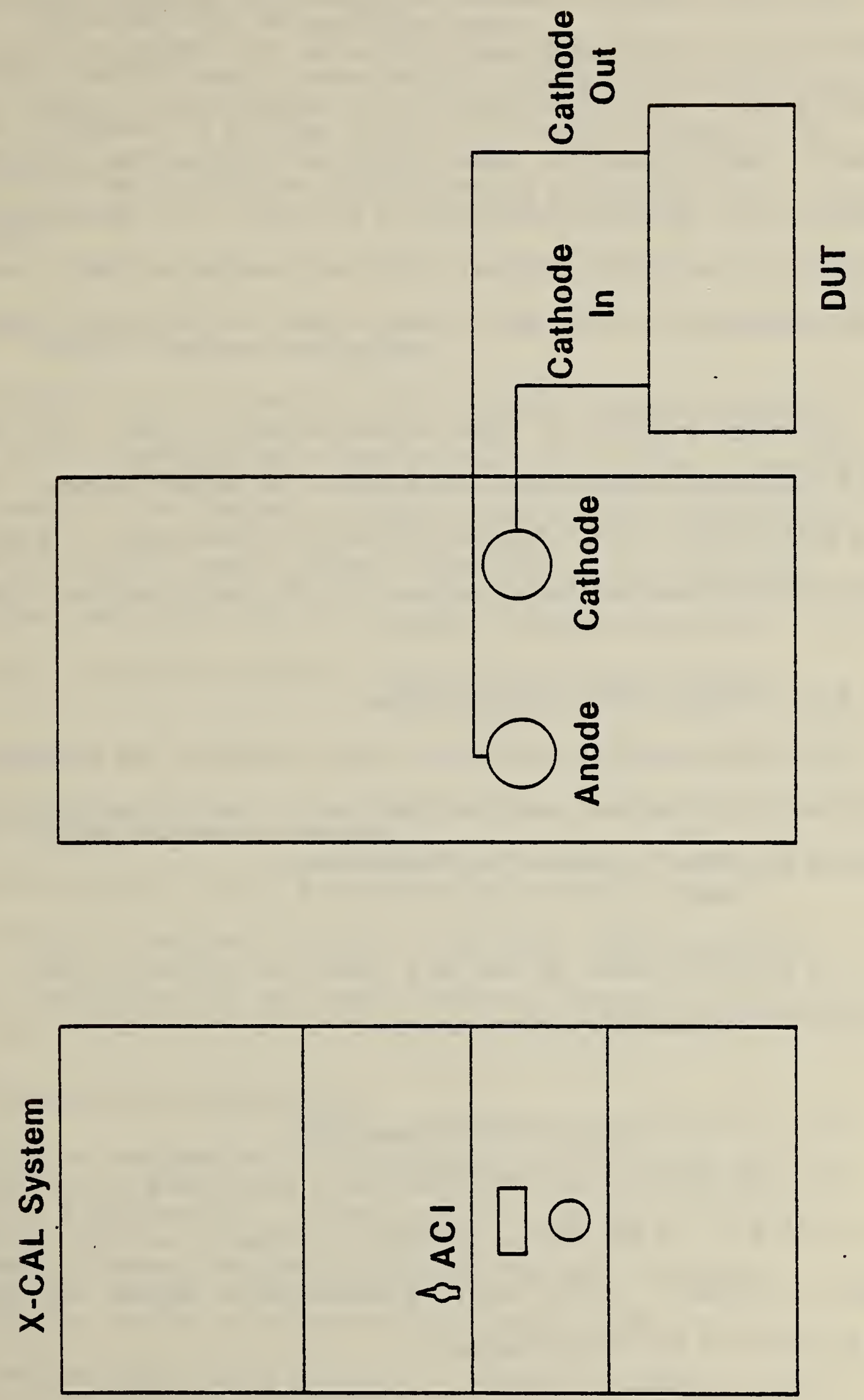
The current pulser is manually triggered with the duty cycle being controlled such that average power dissipation in a $200 \mathrm{ohm}$ load does not exceed 10 watts. The triager switch on the pulser unit is lighted when the system is ready for pulsing. When the system is pulsed, the indicator in the $X$-CAL unit will show the peak current in the pulse. For the Dynalyzer system (divider unit and digital display) which reads average current, a conversion factor between peak current and average current into 200 ohms is given in Table 6.1

The delays involved for higher current pulses are long. For example, with a 2 amp peak current pulse, the minimum time between pulses is $80 \mathrm{~s}$ for a pulse width of $1 \mathrm{~s}$. Pressing the trigger button when it is not lighted cannot cause additional pulses. The DUT should be reset between pulses.

\subsection{Dividers without Display Units}

For dividers with no display units only certain of the procedures described in the sections above are applicable. The following sections indicate the proper procedure for these devices.

The X-CAL system may be used as a comparison system for other dividers and current measurement systems.

\subsubsection{Direct Voltage Divider Measurements}

The calibration system and divider under test should be configured as in Fig. 6.1. If the DUT has no internal readout, a suitable indicator should be provided. In this case, the comparison is between the standard and the DUT plus the chosen readout. 


\subsubsection{Alternating High Voltage Measurements}

To compare the DUT under alternating high voltage with the calibration system, the arrangement is as shown in Fig. 6.2. Here the output of the DUT is compared directly with the standard reading provided by the $X$-CAL system.

\subsubsection{Frequency Response Measurements}

The procedure to be followed in determining the frequency response of the DUT is just that detailed in Section $6.10-6.15$. What is measured in this procedure is the frequency response of the divider in combination with the cable nominally used to connect the divider to its associated readout system. Because of this, the frequency response measurement should be done by using this cable to connect the DUT to the X-CAL system.

\subsubsection{Filament Current Measurements}

The variable supply used as a current source for the filament current calibrator is designed to drive a 1-ohm load. Other loads may be used with the proviso that the output current be 1 imited to 20 amperes or less.

\subsubsection{Anode Current Measurements}

The dc pulser incorporated in the anode-current calibration unit is to be used with a.200-ohm load. If this unit is to be used to evaluate the performance of current measuring devices having input impedances less than 200 ohms, series resistance should be added to the circuit to make the effective load at least 200 ohms. It should be remembered that 
the calibration system indicates peak current in the external load. The conversion between the peak current indicated by the calibration system and the average current determined by the DUT listed in Table 6.1 are for units with nominal $200 \mathrm{ohm}$ loads only. Anode current measuring systems which indicate peak current may be compared directly with the calibration system. The anode current pulser unit cannot be used with systems which require that one side of the current path be connected to ground at the unit under test.

\section{Calibration Information}

Calibration procedures employed in establishing the stated accuracies for the X-CAL system are summarized in the following sections.

The direct high voltage measurement uses as a standard a userprovided Park resistor. A calibration of the active low side was made by using NBS standards and a NBS Park divider. Divider ratios may normally be determined to $\pm 0.1 \%$ levels of uncertainty, so the stated uncertainty of the calibration system of $1.0 \%$ is conservative.

The alternating high voltage measurements were calibrated by direct comparison of the X-CAL system and NBS standards. Both steady state and pulsed voltage levels were utilized. 

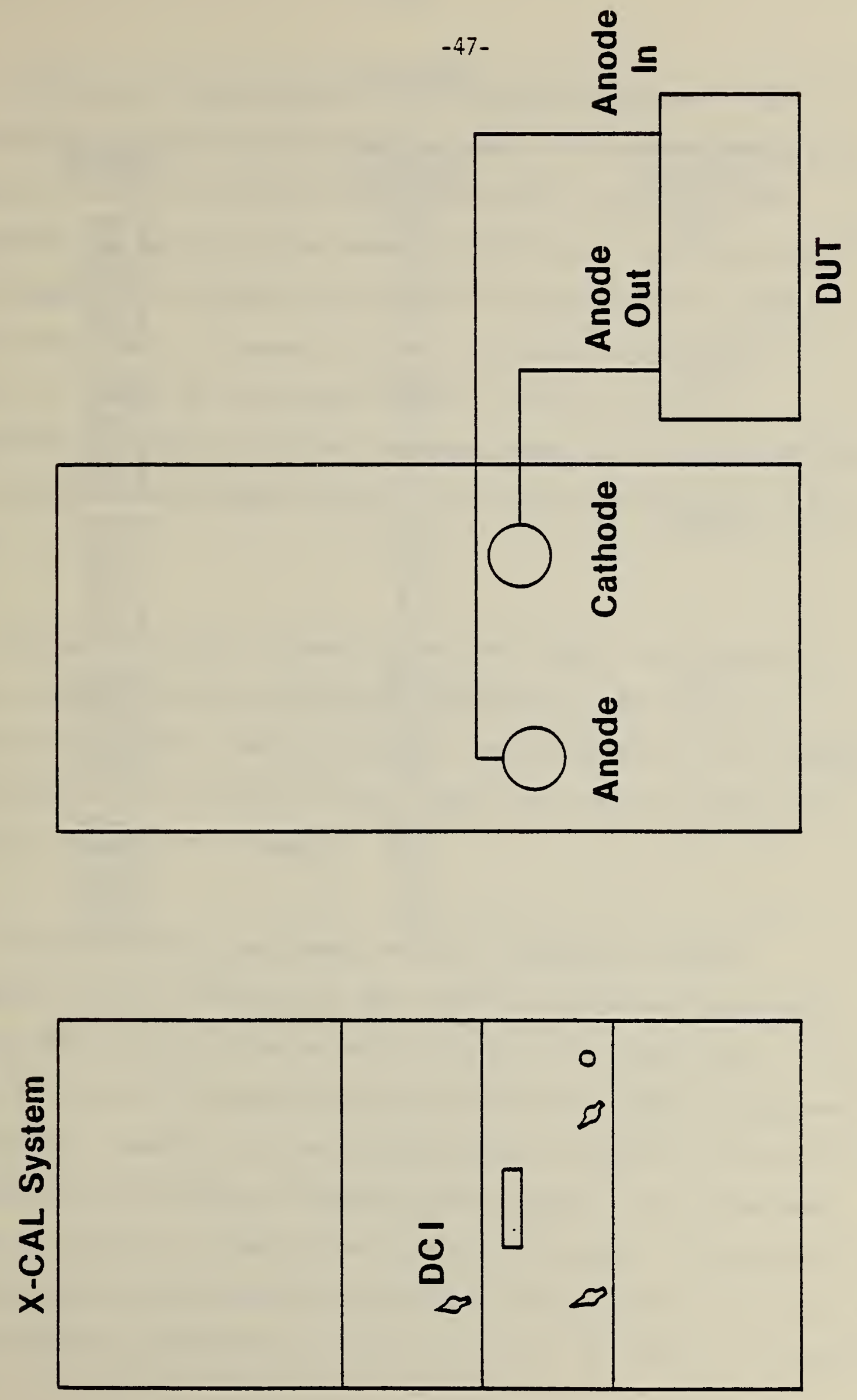

告 
Table 6.1

Peak Current

(amperes)

0.060

0.116

0.602

1.20

1.83

\begin{tabular}{l}
$\begin{array}{c}\text { Pulse Width } \\
\text { seconds }\end{array}$ \\
\hline
\end{tabular}

0.01

0.05

0.1

0.5

1.0

0.01

0.05

0.1

0.5

1.0

0.01

0.05

0.1

0.5

1.0

0.01

0.05

0.1

0.5

1.0

0.01

0.05

0.1

0.5

1.0 $\frac{\text { I average }}{\text { I peak }}$

0.985

0.985

0.980

0.965

0.960

0.975

0.975

0.975

0.970

0.969

0.980

0.960

0.940

0.915

0.910

0.960

0.942

0.910

0.880

0.876

0.967

0.895

0.866

0.875

0.819 
Accuracies of measurements of the frequency dependence of the divider ratio are determined primarily by the ratio transformer accuracy. Vendors of these units maintain standards directly traceable to NBS standards. In addition to the vendor's certificate of accuracy, specific measurements of corrections to the divider ratio were made for $5-\mathrm{kHz}$ and $10-\mathrm{kHz}$ signals. A summary of these corrections is provided in Section 6 . Since the measurement technique involves a nulling procedure, the actual uncertainty in a measurement and the reproducibility of such measurements depends largely on the laboratory techniques of the user.

The accuracy of the filament current measurements was determined using a precision current transformer constructed by NBS personnel and precision current viewing resistors. Proper operation of the filament current module was verified by direct comparison of module readings with a direct reading $0.1 \%$ ac ammeter.

The anode current measurement requires a comparison between the peak current as indicated by the calibration system and the average current over the pulse duration when discharged into a known load, in this case $200 \mathrm{ohm}$. The calibration procedure involved two separate measurements. The voltage drop caused by a current flowing through a precision non-inductive resistor was amplified and sampled by a peak and hold detector. This measurement yields a value for the peak current in the current pulse. The accuracy of this peak reading was determined by observing the voltage across the current viewing resistor with a calibrated fast digitizing scope. By numerically calculating the 
average current of the current pulse for different peak currents and pulse widths a direct relation between peak current and average current was determined. Table 6.1 summarizes the results of this calibration procedure.

\section{Maintenance and Calibration}

There is no routine maintenance required for the X-CAL system. Because of the developmental nature of the system, no explicit procedures for troubleshooting system failures are available. Loss of a particular test function would suggest investigation of the active circuitry involved using conventional voltage checks and signal tracing.

Since the X-CAL system is designed to be used to calibrate $x$-ray dividers in a comparator mode at the $1 \%$ accuracy level, a properly equipped standards lab may routinely check the accuracy of certain units of the system.

The DCHV test uses as a standard for comparison a Park resistor and an active low side with a digital display. By using a second Park divider and associated readout, the X-CAL system may be adjusted to be direct reading. This adjustment is made by means of TRIM I, located on the low side board in the system control module. This board contains three separate active low sides and associated calibration adjustments. TRIM I adjusts the Park divider low side, TRIM II the capacitive divider low side and TRIM III the low side used with passive $x$-ray dividers. Also on the low side board are pairs of trim pots used for zero offset adjustments. The calibration trim pots are nearest the board and are labeled I, II and III. 
The ACHV calibration adjustment TRIM II should only be adjusted if a suitable ac divider system is available.

A third active low side is provided for use with passive dividers. The gain of this system may be adjusted to make the output of a given divider direct reading.

The filament current module uses a current transformer with a precision resistor burden and should maintain accuracy for an extended period barring component failure.

The anode current unit was calibrated using a digitizing scope and would require a similar unit for recalibration. It is suggested that appropriate NBS personnel be contacted for consultation in the event this unit is suspected to be malfunctioning.

Other X-CAL modules are commercially manufactured and the vendors instruction manuals should be used in the event of failure of these units.

\section{Parts List}

No extensive parts 7 ists have been developed for the X-CAL system since no exotic components were used in the system design and most replacement parts required are available from various vendors. It is suggested that spares be acquired for the active components listed below since lead times for procuring most semiconductors are long. 


\section{List of Selected Active Devices}

Device No.

$\mathrm{OP}-2$

OP-16

4085

556

TL-083

8038

Misc. TTL
Vendor ${ }^{1}$

Precision Monolithics

Precision Monolithics

Burr-Brown

Signetics

Texas Instruments

Intersil

Texas Instruments 
10. Circuit Diagrams

The following set of figures are circuit diagrams for svstem modules and intermodule cabling. All component values are indicated on the diagrams. 



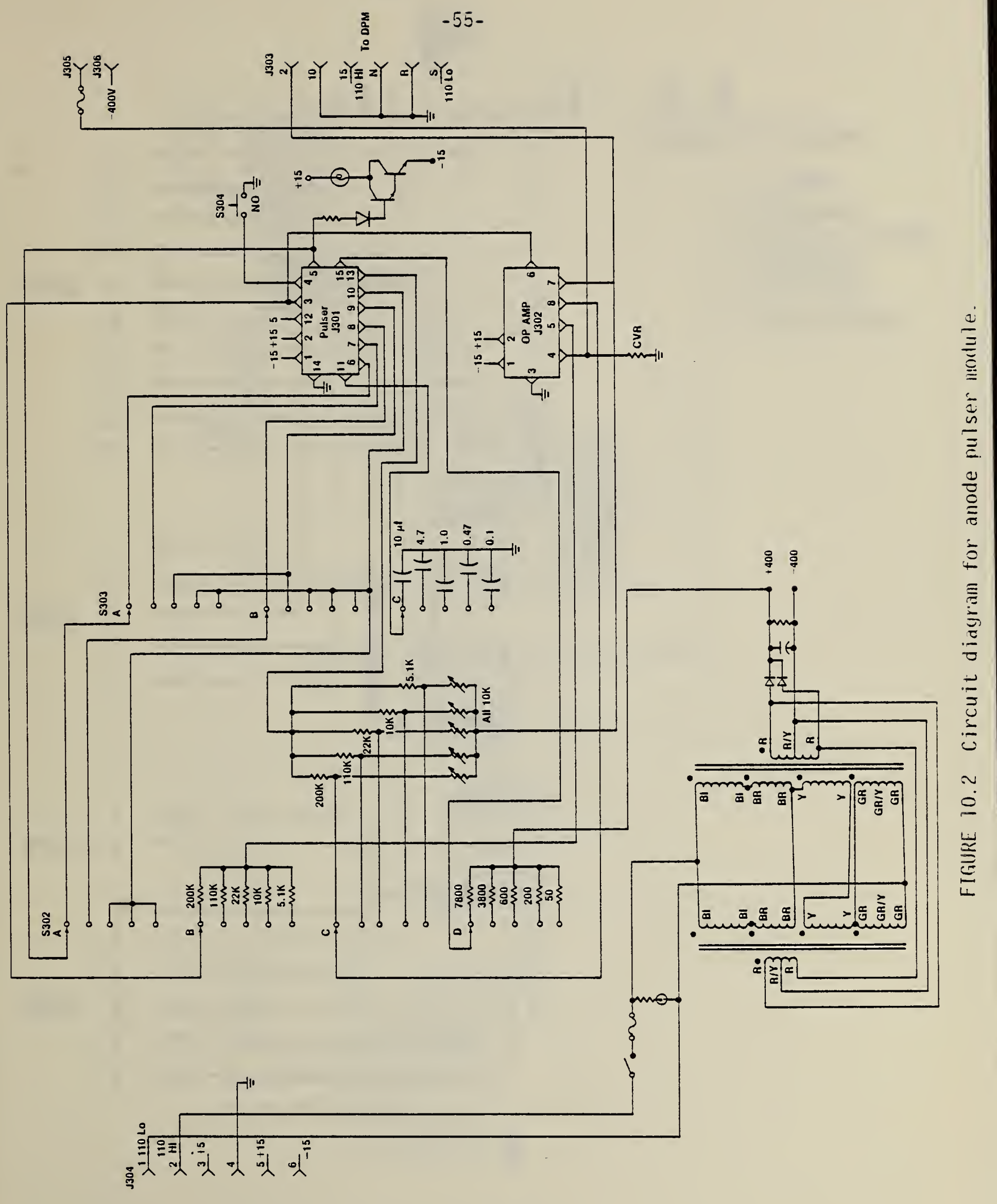




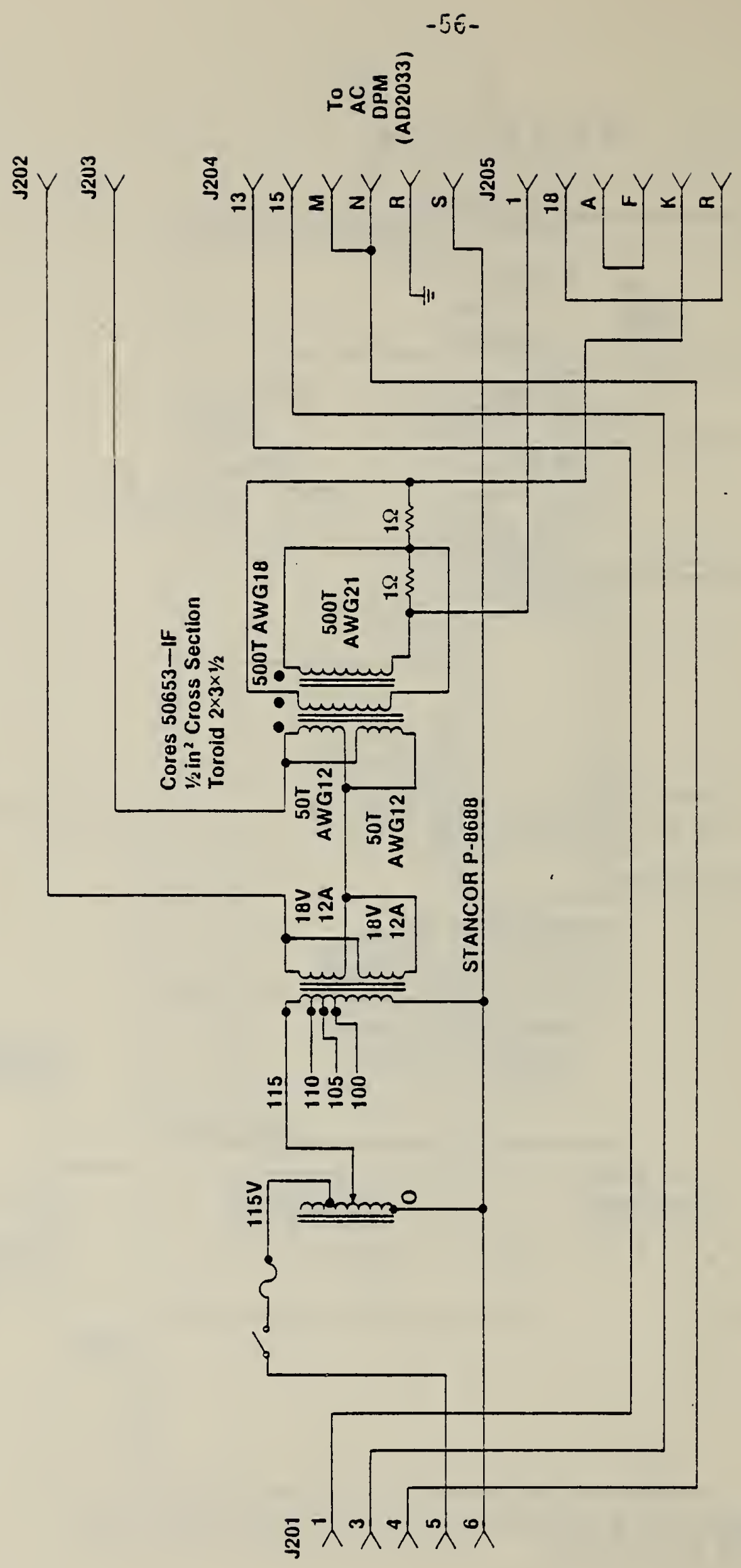




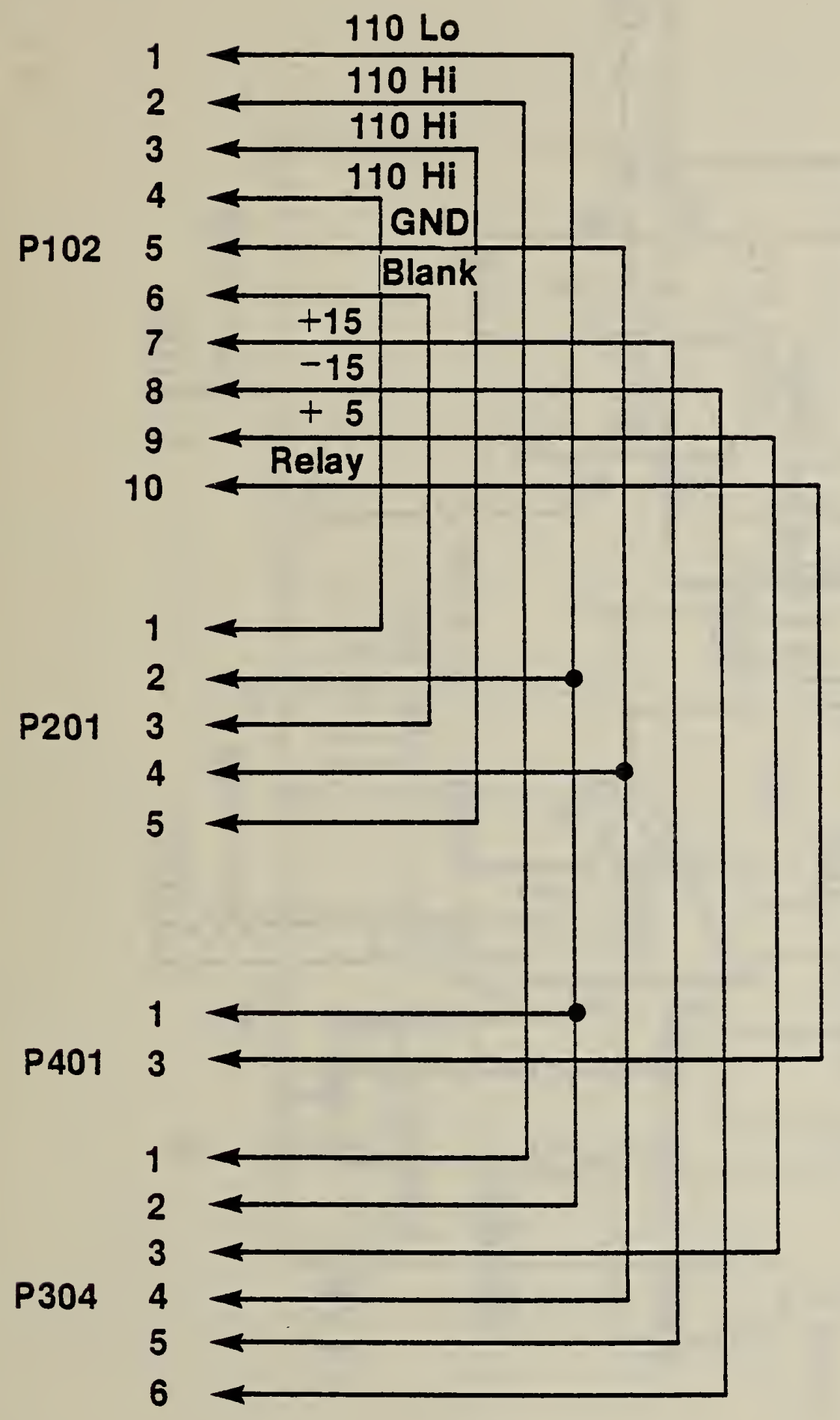

Cables Not Shown
1. \pm 400
2. Filament
3. Output to DUT
4. Interlock
5. AC PWR
6. Input COAX 


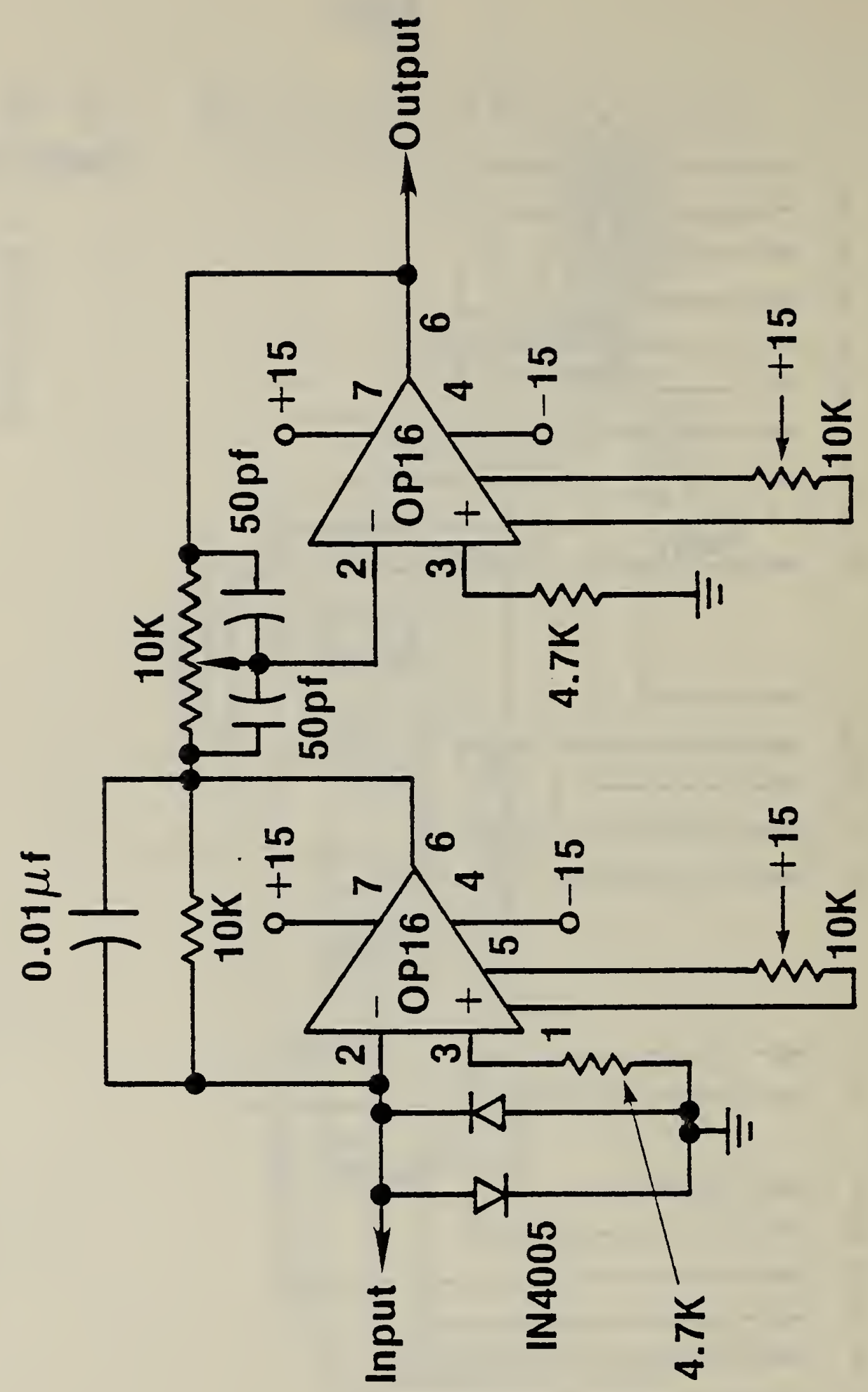




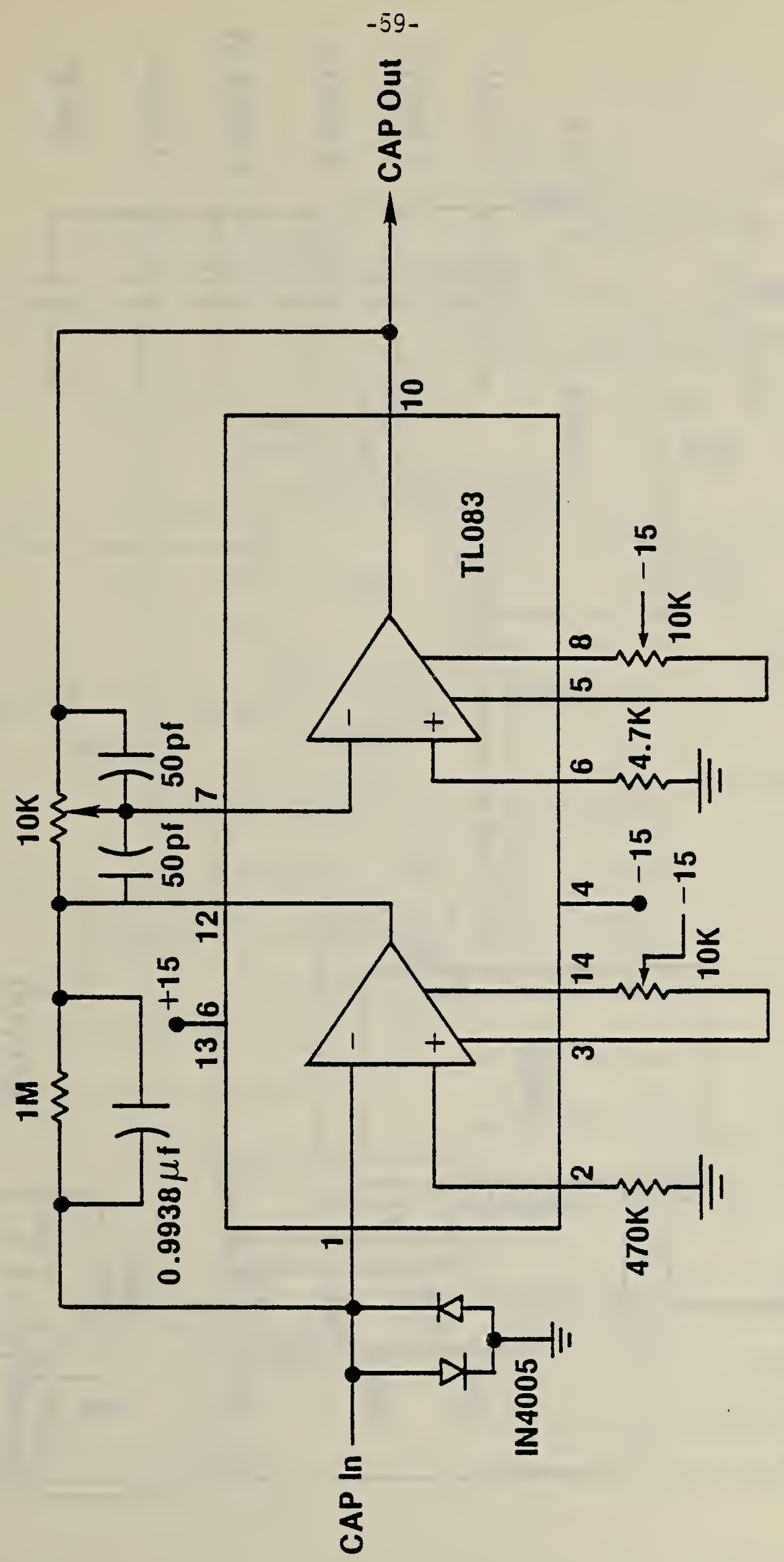

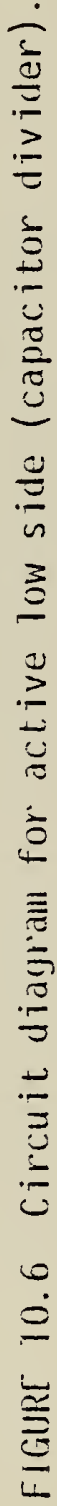




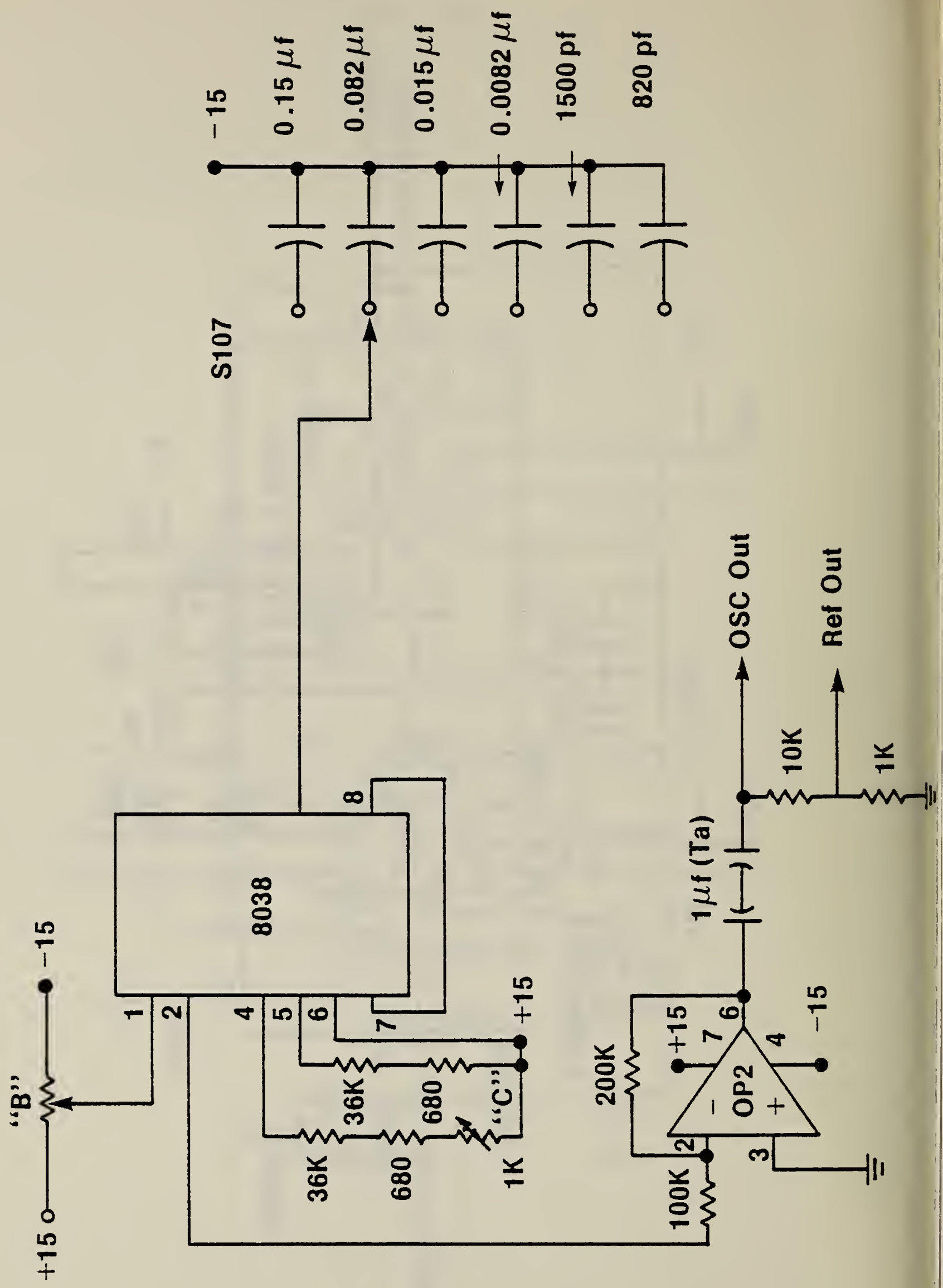


$\leftarrow \frac{1}{2}-15$
$\leftarrow 12$
$\leftarrow \quad 5$

To J301
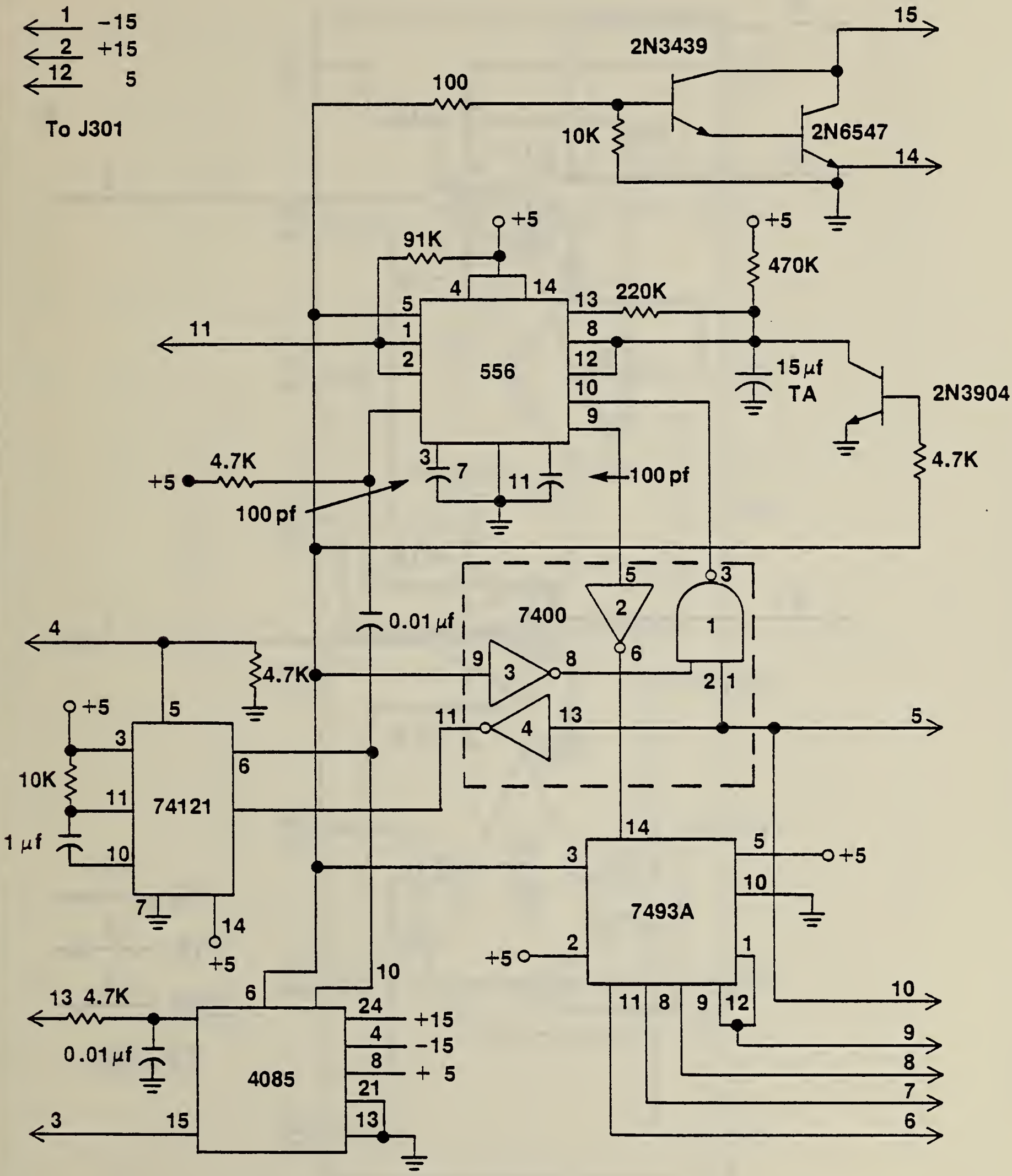

7400
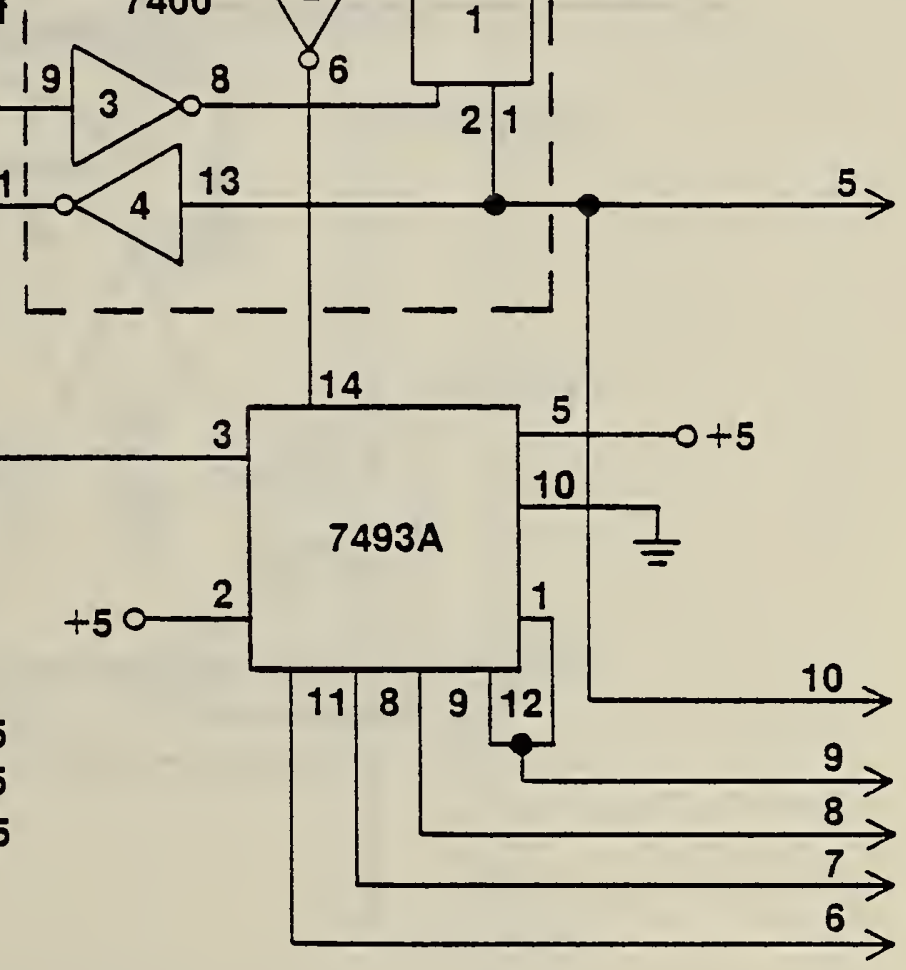

FIGURE 10.8 Circuit diagram for anode pulser controller. 

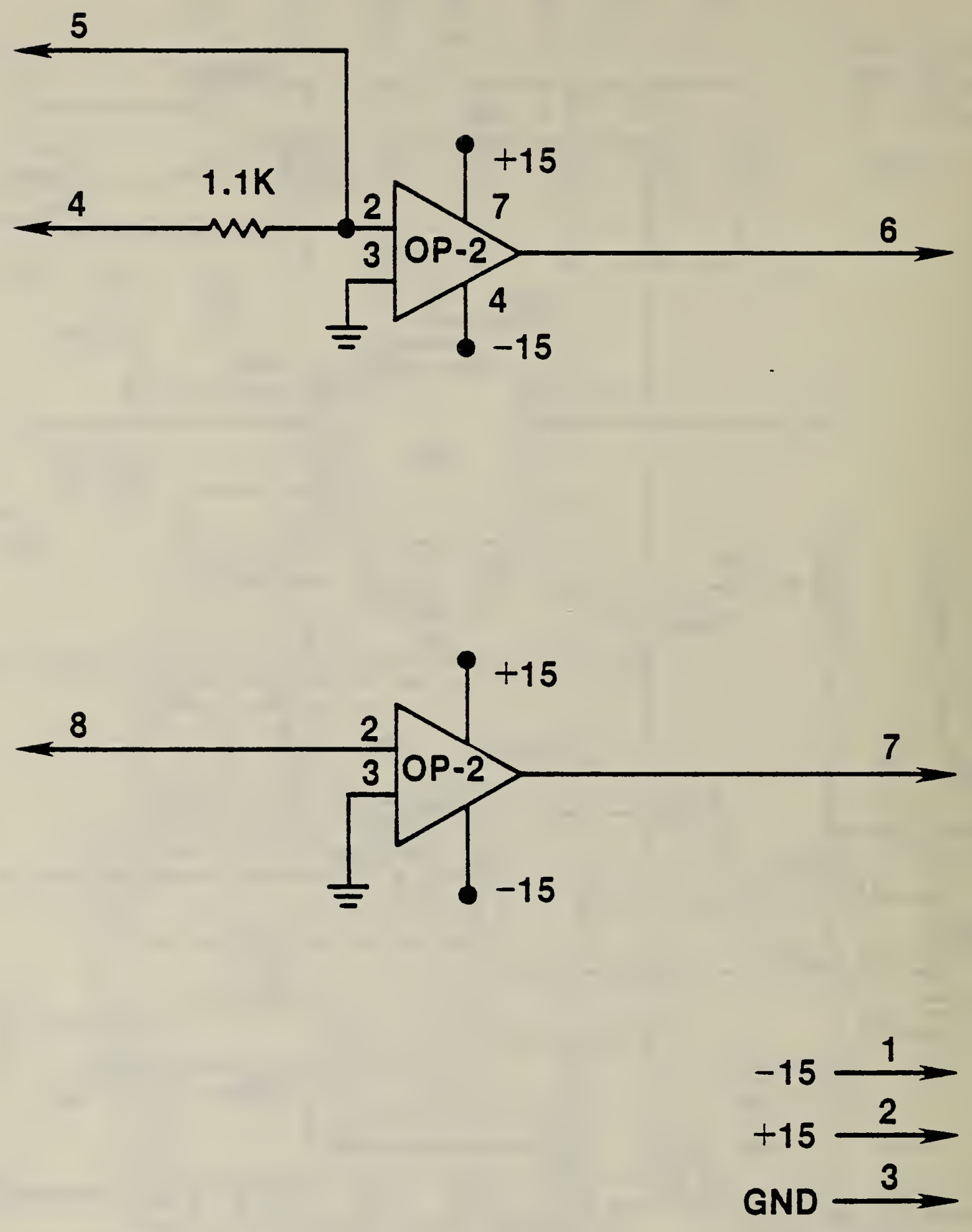

\section{To J302}


-ใว-

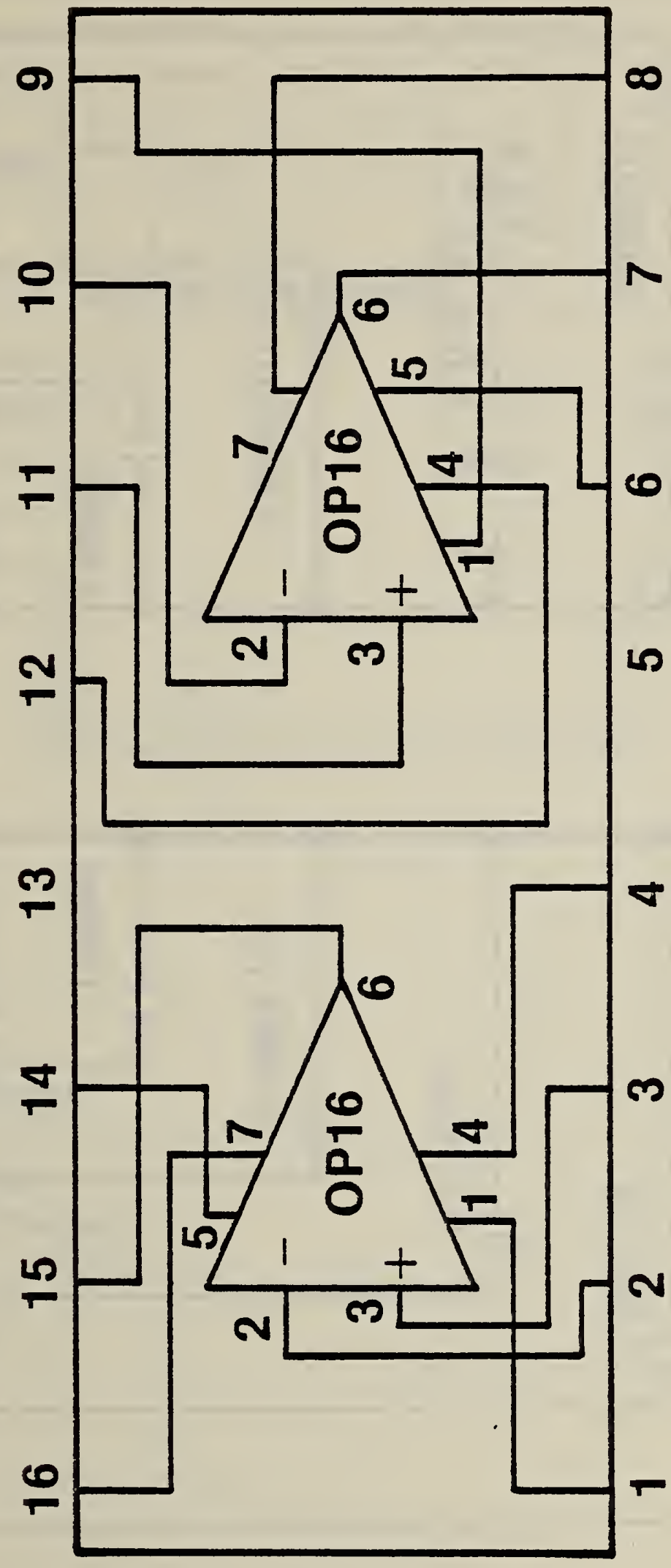

0
0
0
0
0
6
0
0
0
0
0
0
0
0
0
0
0
0
0
0
5
0
0
0
0
0
0
0
0
0
0
0
0
0
0
0
0 
$-64-$
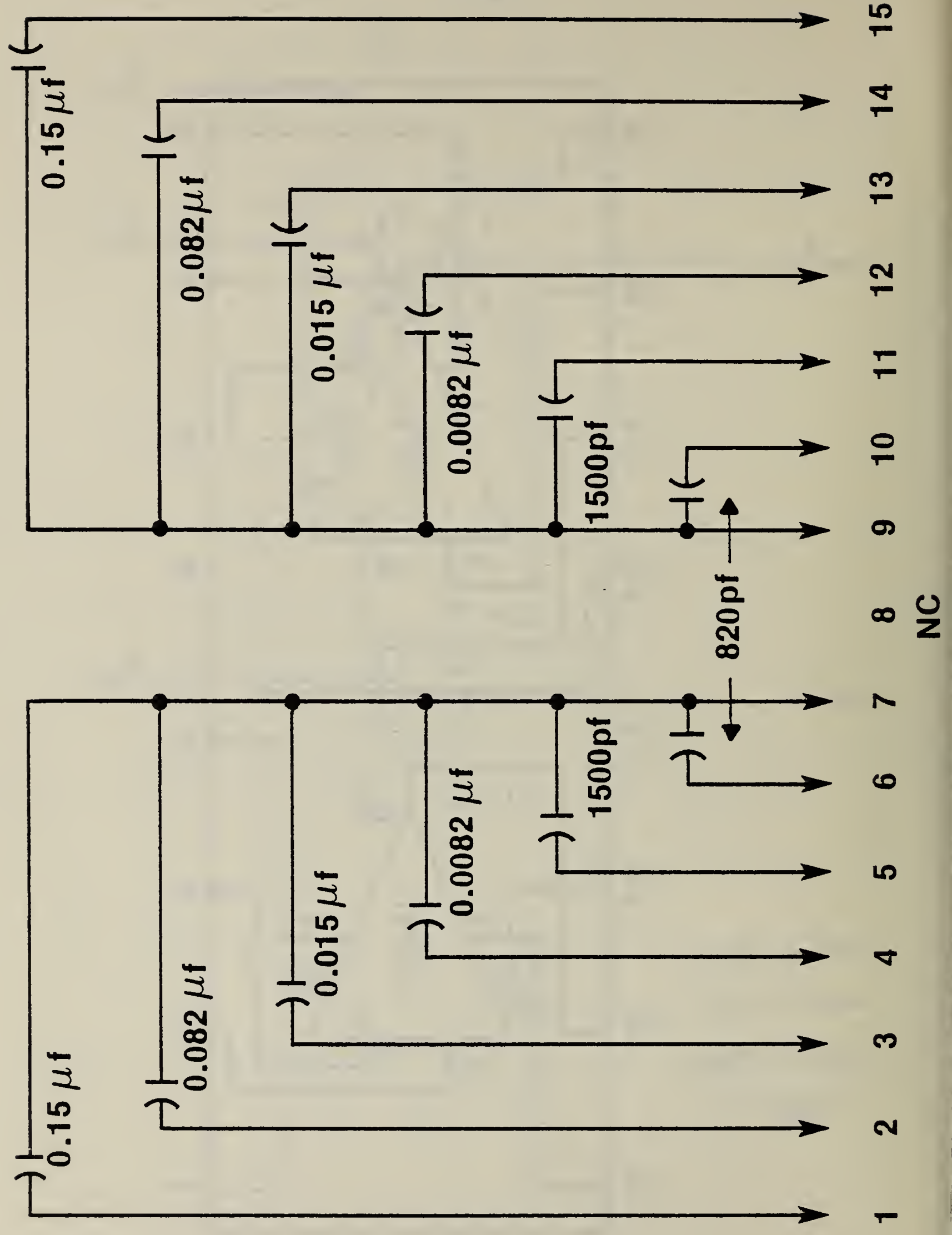


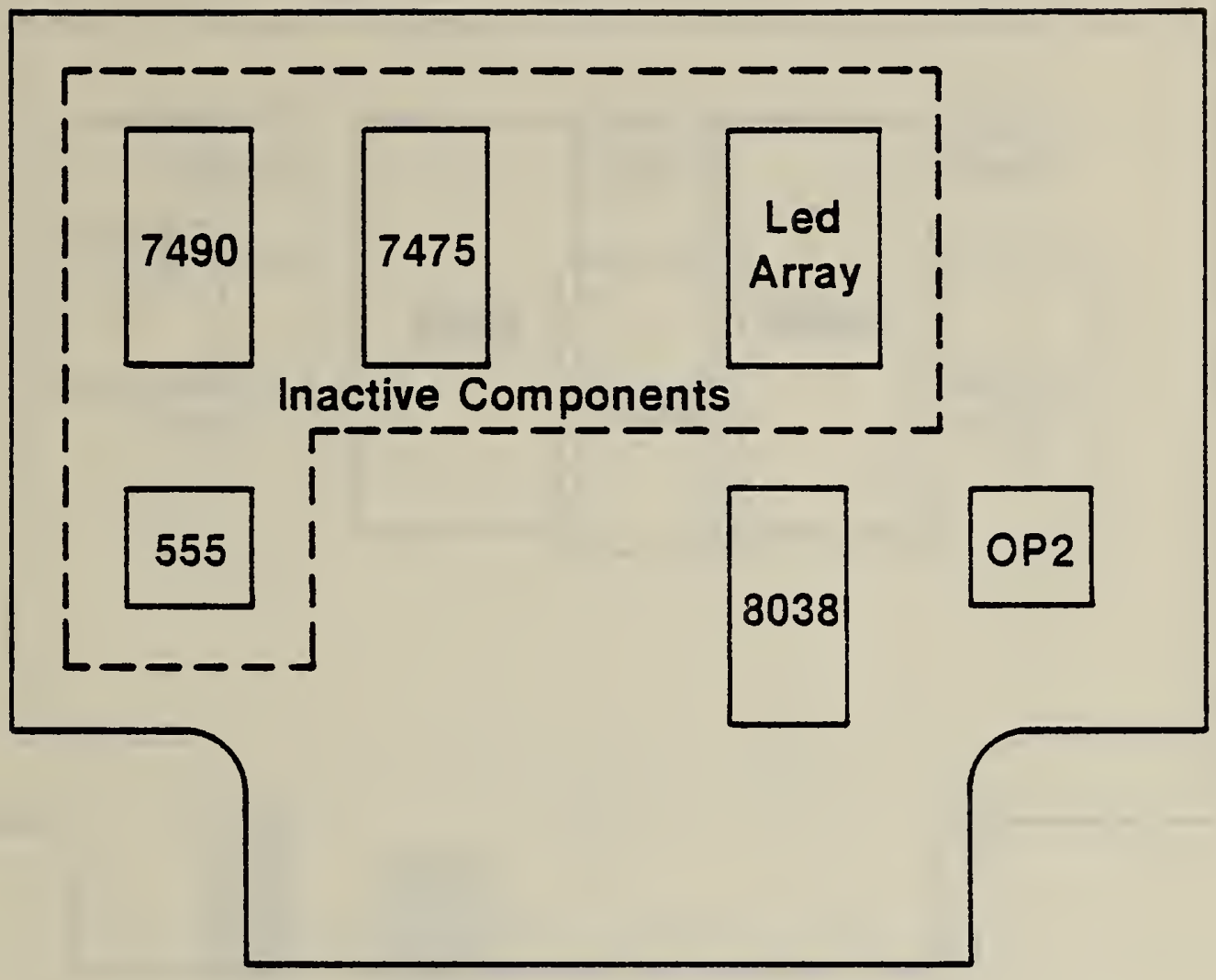

Pins

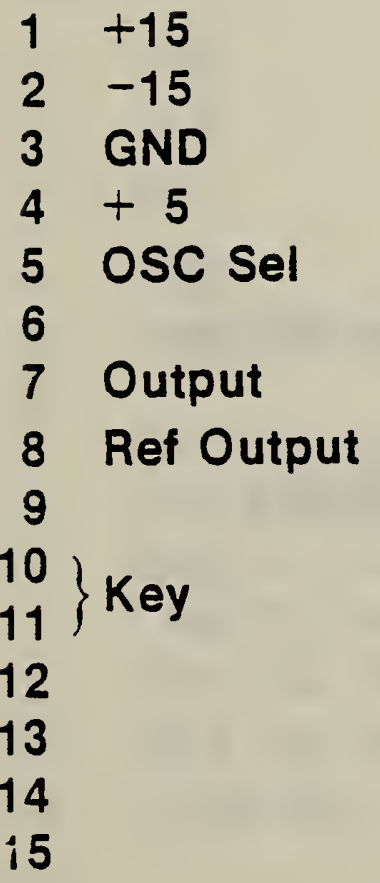

FISURE 10.12 Major parts layout for fixed frequency oscillator board. 

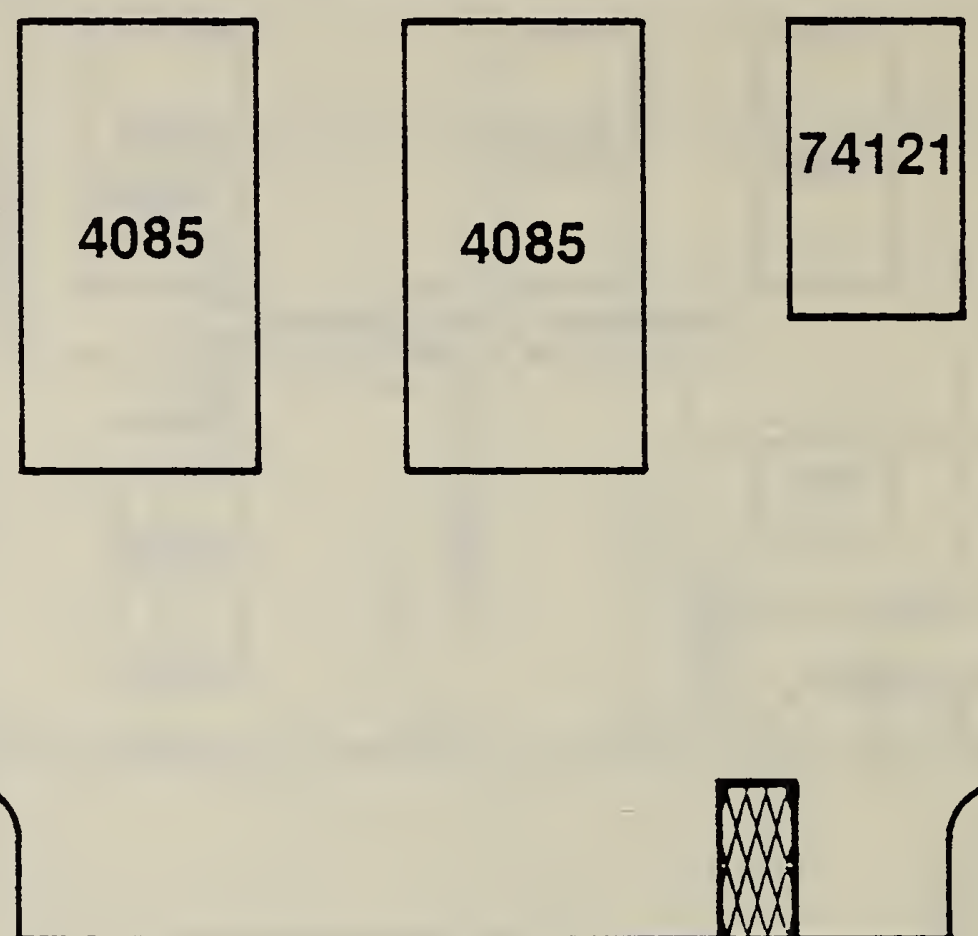

10

\section{PINS}

$1+15$

$2-15$

3 GND

$4+5$

5 P\&H A In (From X-Ray Div. Low Side)

6 P\&H A Out

7 P\&H B In (From Cap Div. Low Side)

8 P\&H B Out

9 Reset (No to GND)

$10 \mathrm{Key}$

FIGURE 10.13 Major parts layout for peak-detect-and-hold hoard. 


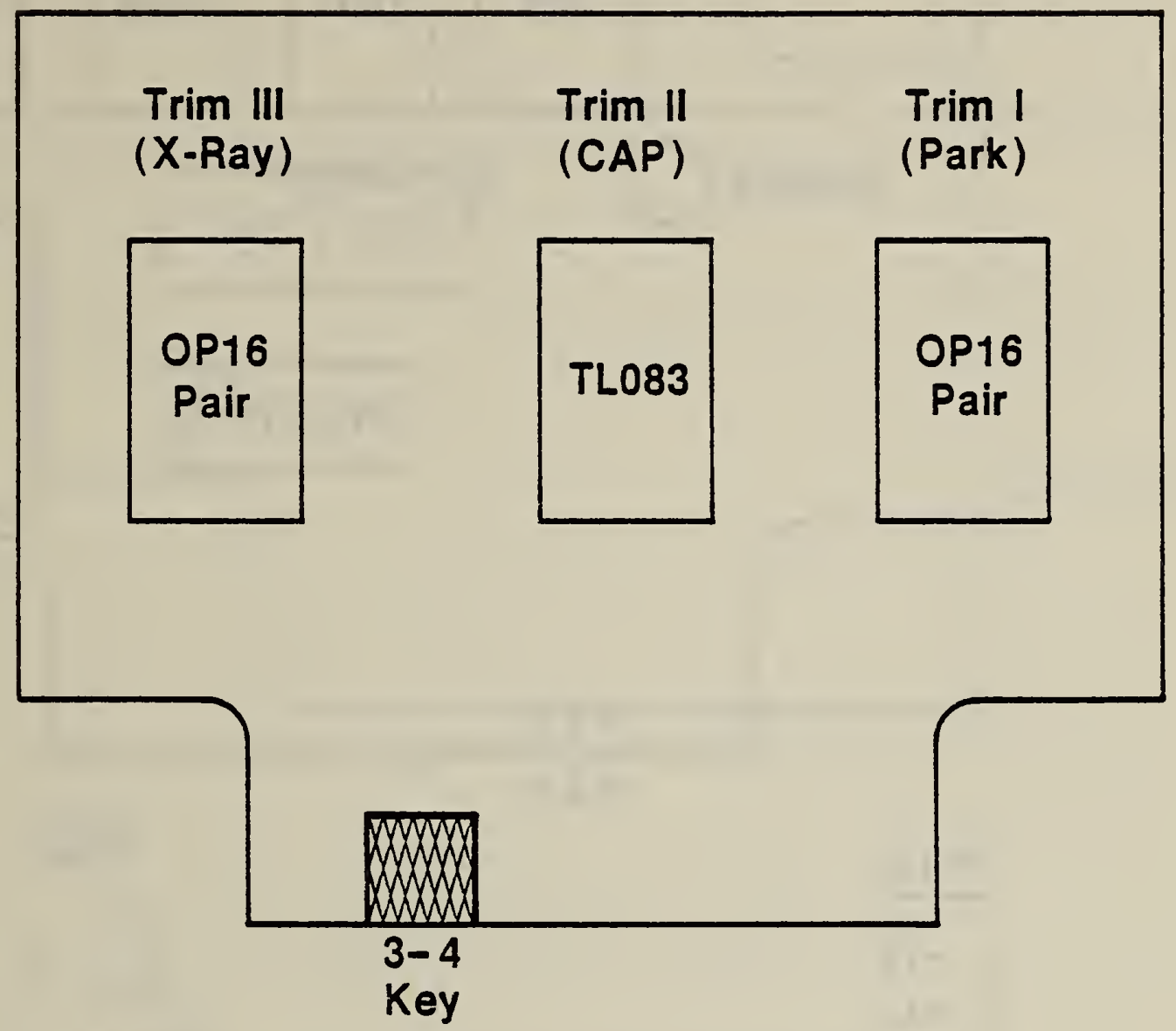

Pins

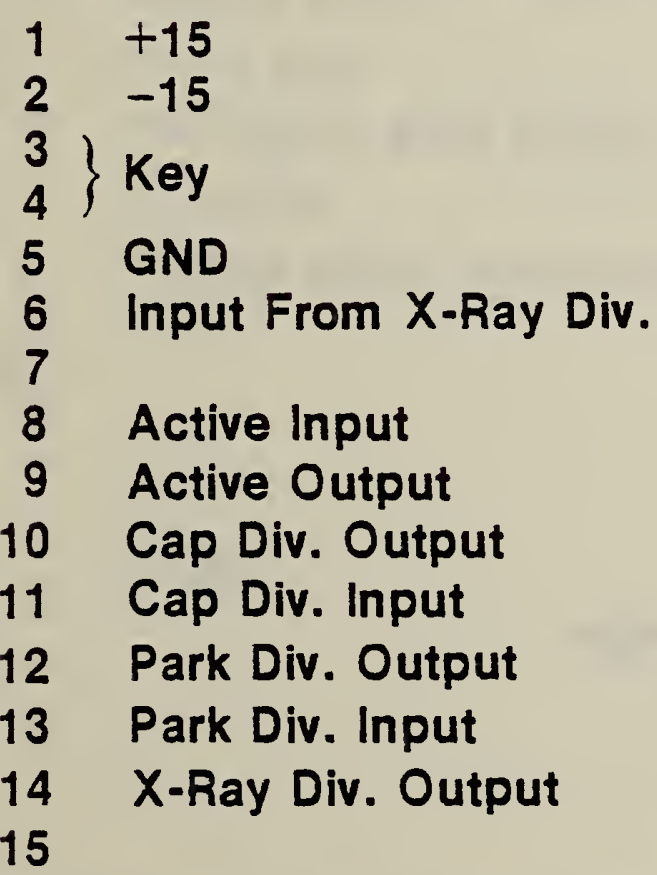

FIGURE 10.14 Major parts layout for active downside board. 


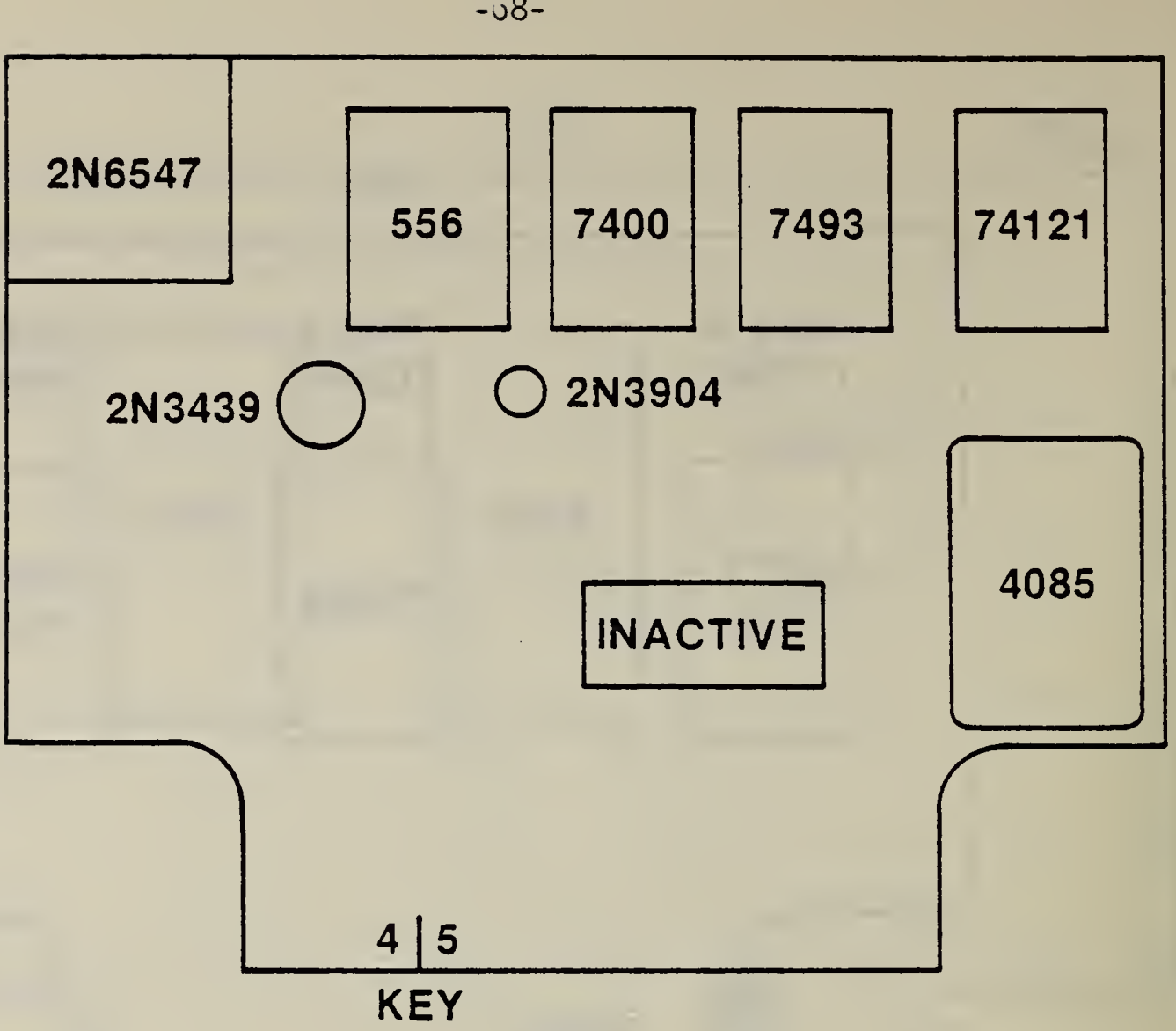

PINS

$1-15$

$2+15$

3 TO CALIBRATION OP AMP

4 TO S 304

5 TO S 302

6 TO S 303

711

811

$9 \quad 11$

10 "II

11 TO S 303

$12+5$

13 FROM CVR OP AMP

14 GND

15 TO S 302

FIGURE 10.15 Major parts layout for anode pulser controller board. 


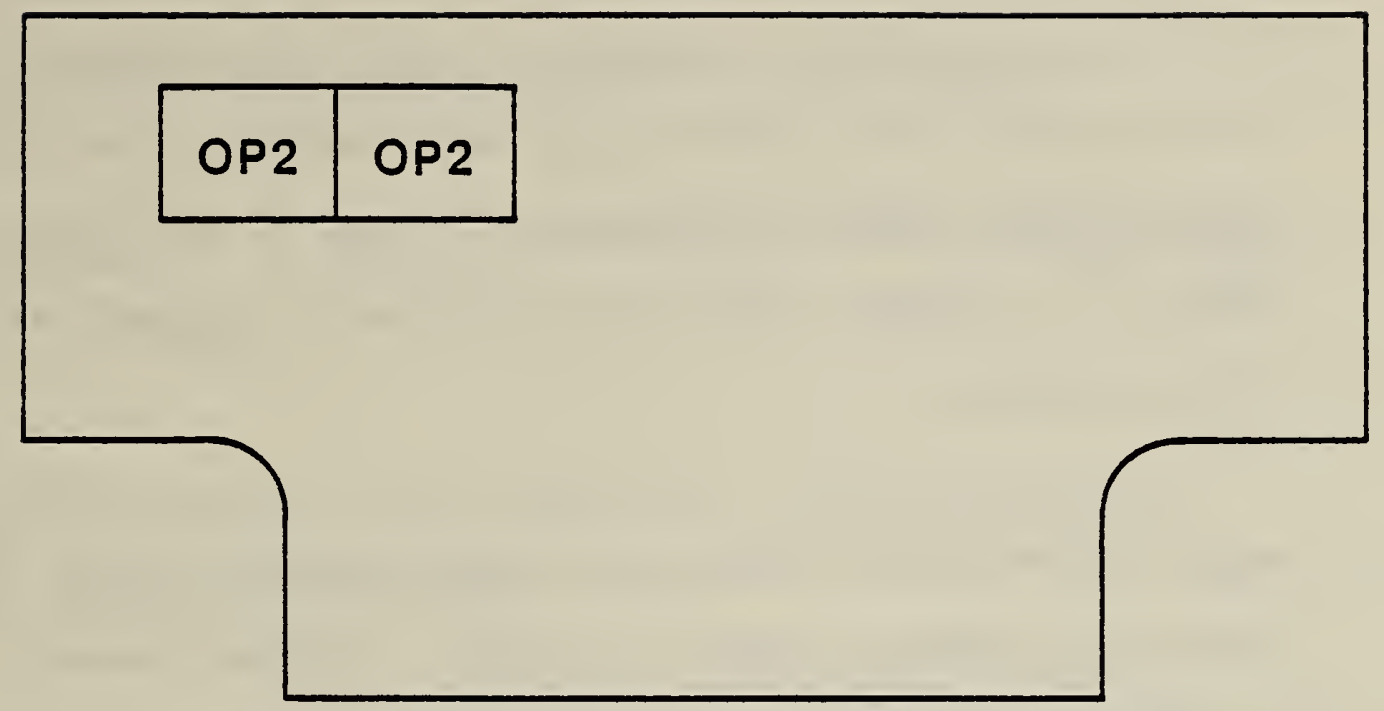

\section{PINS}

$1-15$

$2+15$

3 GND

4 FROM CVR

5 TO S 302

6 TO PEAK AND HOLD

7 TO DPM

8 FROM PEAK AND HOLD

9

10

11

12
13 KEY

14

15

FIGURE 10.16 Major parts layout for anode pulser gain and calibration board. 
11. References

1. Certain commercial equipment, instruments, or materials are identified in this paper in order to adequately specify the experimental procedure. In no case does such identification imply recommendation or endorsement by the National Bureau of Standards, nor does it imply that the material or equipment identified is necessarily the best available for the purpose.

2. Report of the Advisory Committee on the Biological Effects of Ionizing Radiations, National Academy of Sciences - National Research Council, The Effects on Populations of Exposure to Low Levels of Ionizing Radiation (1972).

3. L. Stanton, D. A. Lightfoot, S. Mann, Radiology 87, 87 (1966).

4. P. M. Joseph, Med. Phys. 2, 201 (1975).

5. P. M. Joseph, Med. Phys. 2, 208 (1975).

6. J. C. Giarratano, R. G. Waggener, J. M. Hevezi, and R. J. Shalek, submitted for publication in Med. Phys.

7. G. M. Ardran and H. E. Crooks, Br. J. Radiol. 41, 193 (1968).

8. M. Davison and D. Reekie, Phys. Med. Biol. 13, 643 (1968).

9. E. G. Murphy, unpublished report to Bureau of Radiological Health, FDA, Rockville, Maryland. 
10. J. D. Gilbertson and A. G. Fingerhut, Radiology 93, 1033 (1969).

11. E. R. Epp and H. Weiss, Phys. Med. Biol. 11, 225 (1966).

12. A. F. Jacobson, J. R. Cameron, M. P. Siedband, and J. Wagner, Med. Phys. $\underline{3}, 19$ (1976).

13. International Research Group Renardieres on Impulse Measuring Systems, Electra 35, 157 (1974).

14. In this report, the term "Park divider" is used to denote a divider consisting of a high voltage resistor of the type developed by Park (J. H. Park, J. Research NBS, 66C, 19 (1962)) and an appropriate low side resistor.

12. Acknowledgments

The authors would like to acknowledge the assistance of R. L. Kahler, R. A. Bullock, A. Lomnicki and J. D. Neal in the design and construction of the system and S. B. Kelley in the preparation of this report. 


\begin{tabular}{|c|c|c|c|}
\hline $\begin{array}{l}\text { U.S. OEPT. OF COMM. } \\
\text { BIBLIOGRAPHIC DATA } \\
\text { SHEET }\end{array}$ & $\begin{array}{l}\text { 1. PUBLICATION OR REPORT NO. } \\
\text { NBSIR } 80-2072\end{array}$ & 2.Gov't Accession No & 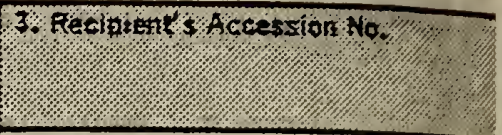 \\
\hline \multirow{2}{*}{\multicolumn{3}{|c|}{$\begin{array}{l}\text { 4. TITLE AND SUBTITLE } \\
\text { X-CAL - A Calibration System for Electrical Measurement } \\
\text { Devices Used with Diagnostic X-Ray Units }\end{array}$}} & $\begin{array}{l}\text { 5. Publication Date } \\
\text { June } 1980 \\
\end{array}$ \\
\hline & & & 6. Pertorming Organization Code \\
\hline \multicolumn{3}{|c|}{$\begin{array}{l}\text { 7. AUTHOR(S) } \\
\text { R.H. MCKnight and R.E. Hebner }\end{array}$} & 8. Performing Organ. Report No. \\
\hline \multicolumn{3}{|c|}{ 9. PERFORMING ORGANIZATION NAME AND ADDRESS } & 18. Project/Task/Work Unit Na \\
\hline \multicolumn{3}{|c|}{$\begin{array}{l}\text { NATIONAL BUREAU OF STANDARDS } \\
\text { DEPARTMENT OF COMMERCE } \\
\text { WASHINGTON, DC } 20234\end{array}$} & $\begin{array}{l}\text { 11. Contract/Grant No. } \\
\text { DoD/CCG Proj. } 78-130\end{array}$ \\
\hline \multirow{2}{*}{\multicolumn{3}{|c|}{$\begin{array}{l}\text { 12. SPONSORING ORGANIZATION NAME AND COMPLETE ADDRESS (Street, City, stato, ZIP) } \\
\text { Combined Calibration Group } \\
\text { U.S. Army Metrology and Calibration Center, Bldg. } 5435 \\
\text { Redstone Arsenal, AL } 35809\end{array}$}} & $\begin{array}{l}\text { 13. Type of Report \& Period Covered } \\
\text { Fina } 1\end{array}$ \\
\hline & & & 14. Sponsoring Agency Code \\
\hline
\end{tabular}

15. SUPPLEMENTARY NOTES

Document describes a computer program; SF-185, FIPS Software Summary, is attached.

16. ABSTRACT (A 200-word or less factual summary of most significant infomation. If document includes a significant bibliography of literature survey, mention it here.)

The X-CAL high-voltage-divider calibration system was designed to calibrate the direct and alternating voltage measurement capabilities of commercial high voltage dividers used to characterize diagnostic $x$-ray units. In addition, there is capability for determining the frequency response of these dividers and for the calibration of the filament current and anode current measurement features of specific commerciallyavailable devices. The calibration system combines in a single unit a range of capabilities which allows calibration of a device under test to be accomplished with a minimum of set up time. This report gives a description of the motivation for, the operation of and the design details of the X-CAL system. It lists the specified accuracies and the ranges of applicable parameters of the various subsystems, describes the five different calibrations which can be performed using the $X-C A L$ system, discusses techniques used in the original calibration of the X-CAL system itself, and contains the basic circuit diagrams for the system.

17. KEY WORDS (six to twelve entres; alphebetical order; capitalize only the first letter of the first key word unless a proper name; separated by semicolons)

Calibration; diagnostic $x$-rays; electrical measurements; health; radiation; radiation safety; safety; $x$-rays.

\begin{tabular}{|c|c|c|}
\hline 18. AVAILABILITY $\quad$ Unlimited & $\begin{array}{l}\text { 19. SECURITY CLASS } \\
\text { (THIS REPORT) }\end{array}$ & $\begin{array}{l}\text { 21. NO. OF } \\
\text { PRINTED PAGES }\end{array}$ \\
\hline E For Official Distribution. Do llot Release to NTIS & UNCLASSIFIED & 75 \\
\hline $\begin{array}{l}\text { - Order From Sup. of Doc., U.S. Government Printing Office, Washington, DC } \\
20402 \text {, SD Stock No. SNOO3-003- }\end{array}$ & $\begin{array}{l}\text { 20. SECURITY CLASS } \\
\text { (THIS PAGE) }\end{array}$ & 22. Price \\
\hline $\begin{array}{l}\text { X Order From National Technical Information Service (NTIS), Springfield, } \\
\text { VA. } 22161\end{array}$ & UNCLASSIFIED & $\$ 7.00$ \\
\hline
\end{tabular}


